OPEN ACCESS

Edited by: Maurice Millet,

Université de Strasbourg, France

Reviewed by:

Keyller Bastos Borges,

Universidade Federal de São João

del-Rei, Brazil

Zhi-Yuan Gu,

Nanjing Normal University, China

*Correspondence: Zhihua Song

zhihuasong08@yeah.net

Jinhua Li

jhli@yic.ac.cn

Specialty section:

This article was submitted to Environmental Analytical Methods,

a section of the journal

Frontiers in Environmental Chemistry

Received: 01 May 2021

Accepted: 12 July 2021

Published: 17 August 2021

Citation:

Sun $D$, Song $Z$, Zhang $Y$, Wang $Y$, Lv M, Liu H, Wang L, Lu W, Li J and Chen $L$ (2021) Recent Advances in Molecular-Imprinting-Based Solid-

Phase Extraction of Antibiotics

Residues Coupled With

Chromatographic Analysis.

Front. Environ. Chem. 2:703961.

doi: 10.3389/fenvc.2021.703961

\section{Recent Advances in} Molecular-Imprinting-Based Solid-Phase Extraction of Antibiotics Residues Coupled With Chromatographic Analysis

\author{
Dani Sun ${ }^{1,2}$, Zhihua Song ${ }^{3 *}$, Yue Zhang ${ }^{2,3}$, Yixiao Wang ${ }^{2,4}$, Min Lv $^{2}$, Huitao Liu ${ }^{1}$, \\ Liyan Wang ${ }^{2,4}$, Wenhui $\mathrm{Lu}^{5}$, Jinhua $\mathrm{Li}^{1,2,4 *}$ and Lingxin Chen ${ }^{2,4}$
}

${ }^{1}$ College of Chemistry and Chemical Engineering, Yantai University, Yantai, China, ${ }^{2}$ CAS Key Laboratory of Coastal Environmental Processes and Ecological Remediation, Shandong Key Laboratory of Coastal Environmental Processes, Research Center for Coastal Environmental Engineering and Technology, Yantai Institute of Coastal Zone Research, Chinese Academy of Sciences, Yantai, China, ${ }^{3}$ School of Pharmacy, Collaborative Innovation Center of Advanced Drug Delivery System and Biotech Drugs in Universities of Shandong, Key Laboratory of Molecular Pharmacology and Drug Evaluation (Yantai University), Ministry of Education, Yantai University, Yantai, China, ${ }^{4}$ School of Source and Environment, University of Chinese Academy of Sciences, Beijing, China, ${ }^{5}$ School of Light Industry and Engineering, Qilu University of Technology (Shandong Academy of Sciences), Jinan, China

Abuse and residues of antibiotics cause great harm to organisms and the environment. Appropriate sample pretreatment is usually required for sensitive determination, because of the low content presence of a variety of antibiotics in complicated matrices. Molecularimprinting-based solid-phase extraction (MISPE) has been widely used for sample pretreatment of antibiotics, using molecularly imprinted polymers (MIPs) as adsorbents. Herein, we comprehensively review the recent advances of MISPE of antibiotics, followed by chromatographic analysis. Various solid-phase extraction (SPE) modes based on MIPS are briefly introduced, such as conventional SPE, dispersive SPE, magnetic SPE, matrix solid-phase dispersion, and pipette-tip SPE. Then, several emerging preparation techniques for antibiotics MIPs are summarized including surface imprinting, nanoimprinting, living/controlled radical polymerization, multitemplate imprinting, multifunctional monomer imprinting, and dummy template imprinting. Subsequently, applications of MISPE to analysis of a variety of antibiotics residues since 2018 are overviewed, including sulfonamides, quinolones, tetracycline, and others. Finally, the preparation and application of antibiotics MIPs are prospected.

Keywords: molecularly imprinted polymers, antibiotics, sample preparation, solid-phase extraction, review, imprinting technique

\section{INTRODUCTION}

Antibiotics are produced by bacteria, molds, or other microorganisms in the course of life, which can interfere with or inhibit the survival of pathogenic microorganisms (Fleming, 1929; Stachelek et al., 2021). They can be categorized into seven main kinds, namely, sulfonamides (SAs), quinolones (QNs), tetracyclines (TCs), macrolides (MALs), chloramphenicol (CAPs), $\beta$-lactams (BLAs), and aminoglycosides (AGs) (Chen et al., 2017; Ming et al., 2021). Besides being widely used to prevent 
and treat animal and human diseases, antibiotics are also widely used as growth-promoting agents in animal husbandry and aquaculture, playing an important role in improving animal and human health (Ming et al., 2021). However, with the increasing use and abuse of antibiotics, bacteria are quickly adapted to the antibiotics, and all kinds of "superbugs" are being born (Stachelek et al., 2021). Consequently, antibiotic residue has become one of the most important environmental issues in the world. The residues and accumulation through various pathways in animals and the environment not only induce the growth of drug-resistant bacteria with increasing numbers and species (Stachelek et al., 2021) but also accumulate toxicity through the food chain, causing great harm to the ecological environment and human health (Liu et al., 2020). It is urgently required to develop effective analytical methods toward antibiotics residues. Chromatography and mass spectrometry (MS) based methods are commonly utilized, especially high-performance liquid-phase chromatography- (HPLC-) and tandem MS (HPLC-MS/MS). Despite high sensitive detection techniques, such as HPLCMS/MS, it is still quite imperative to use influential sample preparation/pretreatment steps prior to detection, owing to the characteristics of low residual amounts, various interfering factors, and complicated sample matrices (Dugheri et al., 2021).

At present, sample pretreatment is widely employed in the analysis of trace analytes in complex matrices to purify and enrich the analytes and thereby will improve the sensitivity and accuracy of analytical methods (Zhang Y. et al., 2020). Currently, solidphase extraction (SPE) that uses solid adsorbent to adsorb the target analytes is commonly used in the process of sample pretreatment, since it has many advantages, such as less timeconsuming, simple operation, high efficiency, low or without solvent, and good compatibility with different analytical methods (Wu et al., 2021). SPE has a variety of modes, mainly including conventional SPE, dispersive SPE (DSPE), magnetic SPE (MSPE), matrix solid-phase dispersion (MSPD), solid-phase microextraction (SPME), stir-bar sorptive extraction (SBSE), and pipette-tip SPE (PT-SPE). It is well known that solid adsorbent is the key parameter of SPE efficiency. Nowadays, commercially available solid adsorbents like HLB, C18, and Oasis MCX usually exhibit nonspecific adsorption on the target analytes, which decrease the selectivity and specificity for antibiotics, thus greatly limiting the application of trace analysis of antibiotics in complicated matrices. Molecularly imprinted polymers (MIPs) with structure predictability, recognition specificity and application universality, easy preparation, low cost, and so on have gained great popularity as SPE adsorbents ( $\mathrm{Li}$ et al., 2013; Chen et al., 2016; BelBruno, 2019; Arabi et al., 2020).

MIPs are prepared by molecular-imprinting technology based on the principle of antigens and antibodies specifically recognizing and binding, and the technology has often been vividly described as the "artificial lock" technology for preparing to recognize "molecular key" (Li et al., 2013). MIPs have been widely used for sample pretreatment (Płotka-Wasylka et al., 2016), chromatographic separation (Wang and Cao, 2015; BelBruno, 2019), chemical/biosensors (Chen et al., 2016; Gaudin,
2020; Arabi et al., 2021), and other fields (BelBruno, 2019; Haupt et al., 2020). Using MIPs as the adsorbents in SPE, molecularly imprinted or molecular-imprinting-based SPE (MISPE) can specifically recognize targets, which can effectively adsorb targets in complex matrices. Therefore, MISPE is extensively used for the highly selective cleanup and enrichment of trace antibiotics in complex samples. Furthermore, MISPE combined with separation and detection technologies such as chromatography has been swiftly developed and applied to achieve rapid, simultaneous, selective enrichment, and sensitive detection of multiple antibiotics contaminants ( $\mathrm{Li}$ and Row, 2017; Wang J. et al., 2018; Wang S. et al., 2018; Hu et al., 2018; Zhu et al., 2019b; Lu et al., 2019).

Therefore, in this work, the application of MISPE coupled with chromatographic analysis of antibiotics is reviewed comprehensively, focusing on the recent advances since 2018. Firstly, the classification of SPE and the commonly used advanced preparation techniques of MIPs are overviewed. Then, the applications of MISPE for the analysis of a variety of antibiotics are emphasized. Finally, some attempts to facilitate the wide application of MISPE in the field of sample pretreatment are proposed.

\section{VARIOUS SPE MODES BASED ON MIPS}

SPE is a technology to separate the component to be tested from the interfering component by the difference of the adsorption ability of solid adsorbent on each component in the liquid sample. The separation efficiency is increasing with the improvement of the selectivity of solid adsorbent toward target analyte (Fan, 2020). Therefore, the use of highly selective MIPs as SPE adsorbent can achieve efficient extraction and enrichment of target analytes, which has been widely used in antibiotics residues detection (Lian and Wang, 2018; Xie et al., 2018; Hammam et al., 2019; Negarian et al., 2019; Zhu et al., 2019b; Tan et al., 2020; Yu et al., 2020). Various SPE modes based on MIPs, i.e., conventional SPE, DSPE, MSPE, MSPD, SPME, SBSE, and PT-SPE, are briefly introduced below.

SPE generally means the conventional SPE, namely, packed SPE, and it is a common method for sample preparation. The column is packed with a solid adsorbent to make the sample be tested flow through the column so that the solid adsorbent can adsorb the target compounds, and then the target compounds can be separated and enriched by chemical reagent elution or heating desorption. The high selectivity of MIPs can greatly improve the extraction efficiency of SPE. The SPE with MIPs as extraction adsorbent has been widely used in the determination of antibiotics (Huang L. et al., 2019; Ma and Row, 2019; Qin et al., 2020).

DSPE does not need the packing and washing steps, the extraction time is short, and the adsorbent can be more fully dispersed into the sample solution to improve the adsorption effect. After the purified sample is shaken and centrifuged, the supernatant can be directly or simply processed into the next step of the analysis. This method proves to be quick, easy, cheap, effective, rugged, and safe and is also known as the QuEChERS method. As an efficient and rapid sample pretreatment 
technology, DSPE is widely used in the analysis and detection of contaminants and antibiotics residue analysis (Song et al., 2018; Lu et al., 2019).

MSPE is a technique in which a magnetic or magnetizable material is used as a solid adsorbent for SPE. Instead of being packed in the extraction column, a magnetic adsorbent is directly added to the sample solution or suspension so as to attain a full dispersion. The target analyte is adsorbed on the surface of the dispersed magnetic adsorbent, and an external magnetic field is utilized to separate the target analyte from the sample matrix (Liang J. et al., 2018). MSPE requires only low consumption of adsorbents and equilibrium time to realize the enrichment and separation of trace analytes. MSPE can avoid column blockage, which is a very important problem in traditional SPE (Li et al., 2019). Magnetic MIPs (MMIPs) materials have been widely used in the detection of many types of antibiotics (Liu et al., 2017; Nazario et al., 2017; Kunsa-Ngiem et al., 2018; Li Z. et al., 2018; Qin et al., 2019; Dil et al., 2021; Gao et al., 2021; Lamaoui et al., 2021).

MSPD is the basic process as follows: adding solid-phase adsorption materials directly to the sample matrix, mechanical mixing resulting in a semidry mixture, using the obtained mixture as a packed column, cleaning the column with a small amount of reagent to remove impurities, and finally eluting the target analyte by a small amount of eluent. MSPD combines with sample crushing, extraction and purification, which not only avoids sample loss but also save solvent/time. MSPD has the advantages of simple and quick operation, high extraction efficiency, no special equipment, and so on; large quantities of automatic analysis can be carried out through MSPD. Therefore, MSPD is widely used in the analysis of antibiotics residues (Wang S. et al., 2018; Soares et al., 2021), contaminants (Liang et al., 2019), and harmful components (Tang et al., 2019). As a kind of solid-phase adsorbent with high selectivity, MIP has been used in MSPD, which provides powerful technical support for the analysis of pollutants (Wang S. et al., 2018) and harmful components (Balsebre et al., 2018) in a complex matrix.

SPME is a solvent-free pretreatment method developed on the basis of SPE. It is easy to be combined with gas chromatography (GC), HPLC, and capillary electrophoresis (CE), so it has been widely used (Barahona et al., 2019; Huang S. et al., 2019; Guo et al., 2020). SPME has been successfully applied in the analysis of organic and inorganic substances in gas, water, soil, sediment, and other environmental samples (Reyes-Garces et al., 2018). SPME process is actually the adsorption/desorption process of each component in the sample on the surface of the extracted fiber coating, and its principle depends on the distribution balance between the analyte in the sample matrix and the extraction phase. By selecting different groups of coating heads, SPME can attain ideal extraction efficiency toward targeted components, while other components are restrained. The MIP coating, because of its simple preparation, good repeatability, high mechanical strength, good resistance to high temperature, and solvent resistance, especially the advantage of efficient choice specificity for trace target in complex environment medium analysis, has a broad application prospect and become a research hotspot of selective SPME coatings (Barahona et al., 2019; Liu et al., 2019).

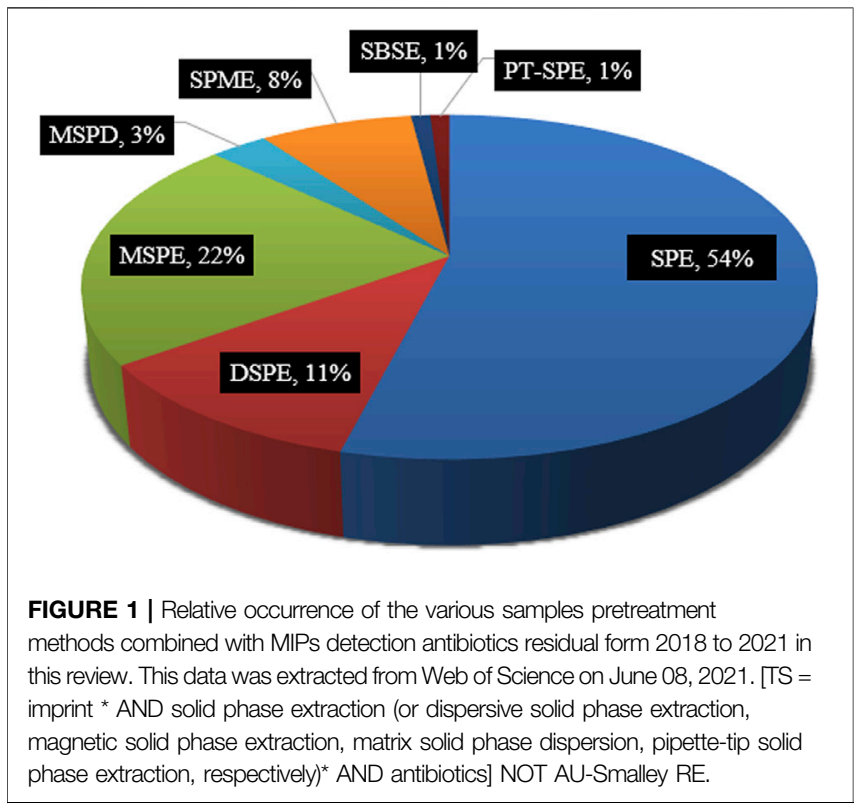

SBSE is a variant of SPME, in which the glass tube with an inner magnetic core is coated with an extractive adsorption coating. After the distribution balance between the sample matrix and the coating on the surface of the stirring rod is reached, the sample is analyzed by thermal desorption or solvent desorption technology. Polydimethylsilane (PDMS) is the widely used coating material of SBSE. The coating prepared by the sol-gel method is compact in structure, highly hydrophobic, and stable in chemical properties. It is suitable for the extraction of nonpolar and weak polar compounds in the water phase. The SBSE has been developed to improve the sensitivity by using a larger volume of extraction phase. The difference is that a magnetic core is required for self-stirring to accelerate mass transfer, as thicker extractive coatings are usually prepared. However, since the SBSE format with magnetic agitation is not as convenient for sampling in vivo or in the field as fiber and film shapes, SBSE is commonly used for in-bottle extraction (RodriguezGomez et al., 2018). However, the MIP coating-based SBSE is rarely used in antibiotic detection (Cui et al., 2021; Yang et al., 2017).

PT-SPE fills the pipette head with an adsorbent, making SPE setup smaller and analysis more environmentally friendly. PT-SPE is currently the most concerned SPE modes, mainly because it requires fewer adsorption materials, significantly reduces organic solvents consumption, and saves the cost. This method is simple and does not need extra special instruments. The transfer and distribution mechanism of the analytes to be enriched is roughly the same as that of the traditional SPE. The eluted solution can be directly used for LC or MS analysis without vacuum concentration. The pipetting nozzle can realize sampling, purification, enrichment, and quantification, at the same time, which makes up for the technical defects of traditional pretreatment methods, such as complicated operation, large amount of organic solvent, and easy loss of targets (de Oliveira et al., 2016; Teixeira et al., 2018; Zhang Y. et al., 2020; Hashemi et al., 2019).

Relative occurrence of the above-mentioned MISPE toward antibiotics residues detection within 2018-2021 is shown in 
TABLE 1| The main characteristics, advantages, and disadvantages of SPE.

\begin{tabular}{|c|c|c|c|c|}
\hline $\begin{array}{l}\text { SPE } \\
\text { mode }\end{array}$ & Schematic & Main characteristics & Advantage & Disadvantage \\
\hline SPE & & $\begin{array}{l}\text { No phase separation operation; easy to } \\
\text { realize automatic batch processing. }\end{array}$ & $\begin{array}{l}\text { Simplicity and flexibility; influential clean up; } \\
\text { having high enrichment factor; high recovery rate } \\
\text { and wide application. }\end{array}$ & $\begin{array}{l}\text { High consumption of organic solvents and } \\
\text { sorbent; incompatible with solid sample; } \\
\text { channeling or blockage of cartridge. }\end{array}$ \\
\hline DSPE & & $\begin{array}{l}\text { No need to wash; short extraction time; the } \\
\text { adsorbent can be more fully dispersed into } \\
\text { the sample solution to improve the } \\
\text { adsorption effect. }\end{array}$ & $\begin{array}{l}\text { Higher efficiency and faster compared with } \\
\text { packed SPE; no need of conditioning; short } \\
\text { extraction consumption of organic solvents. }\end{array}$ & $\begin{array}{l}\text { Possibility of spoiling the sorbent in } \\
\text { complex sample; incompatible with solid } \\
\text { sample; remaining residual of sorbent } \\
\text { sample solution. }\end{array}$ \\
\hline MSPE & & $\begin{array}{l}\text { Magnetic and magnetically modified } \\
\text { adsorbents have high adsorption extraction } \\
\text { capacity. }\end{array}$ & $\begin{array}{l}\text { Simplicity of operator; high selectivity; short } \\
\text { extraction time and low cost; green; large specific } \\
\text { surface area; superparamagnetism; multiple } \\
\text { adsorption sites. }\end{array}$ & $\begin{array}{l}\text { Magnetic nanoparticles }\left(\mathrm{Fe}_{3} \mathrm{O}_{4}\right) \text { have poor } \\
\text { selectivity and affinity for oxidation, } \\
\text { aggregation, and adsorption; fewer } \\
\text { varieties available; some materials are } \\
\text { magnetically unstable; the practical } \\
\text { application device is not perfect and the } \\
\text { degree of automation is low. }\end{array}$ \\
\hline MSPD & 兄 & $\begin{array}{l}\text { Extraction, filtration, and purification can be } \\
\text { completed in one step without the need for } \\
\text { tissue homogenization, precipitation, } \\
\text { centrifugation, pH adjustment, and sample } \\
\text { transfer, thus avoiding the loss of samples. }\end{array}$ & $\begin{array}{l}\text { Simple usage; cost effectiveness; compatible } \\
\text { with all liquid, semisolid, and solid samples. }\end{array}$ & $\begin{array}{l}\text { High backpressure or blocking the } \\
\text { cartridge; inability to reuse the sorbent. }\end{array}$ \\
\hline SPME & & $\begin{array}{l}\text { Sampling and enrichment are carried out } \\
\text { simultaneously; combined with GC, } \\
\text { sampling, enrichment, and injection can be } \\
\text { achieved in one step to reduce sample loss; } \\
\text { matrix consumption can be ignored; suitable } \\
\text { for field sampling and analysis. }\end{array}$ & $\begin{array}{l}\text { Compatible with liquid, gaseous, and solid } \\
\text { samples; solvent-free technique; clean } \\
\text { extraction; ease of automation. }\end{array}$ & $\begin{array}{l}\text { High cost; lack of robustness; bending the } \\
\text { needle; breaking the fiber; flawed } \\
\text { extraction. }\end{array}$ \\
\hline SBSE & & $\begin{array}{l}\text { Sample is analyzed by thermal desorption or } \\
\text { solvent desorption technology; no external } \\
\text { agitator is needed, competitive adsorption } \\
\text { can be avoided, and extraction enrichment } \\
\text { can be realized while stirring itself. }\end{array}$ & Simplicity; high preconcentration capacity. & $\begin{array}{l}\text { Time-consuming and error-prone manual } \\
\text { extraction steps; high solvent consumption. }\end{array}$ \\
\hline $\begin{array}{l}\text { PT- } \\
\text { SPE }\end{array}$ & & $\begin{array}{l}\text { By filling the pipette head with an adsorbent, } \\
\text { the eluted solution can be directly used for LC } \\
\text { or MS analysis without vacuum } \\
\text { concentration. The pipetting nozzle } \\
\text { simultaneously completes sampling, } \\
\text { quantification, purification, and enrichment, } \\
\text { which makes up for the technical defects of } \\
\text { traditional pretreatment methods such as } \\
\text { complicated operation, large amount of } \\
\text { organic solvent, and easy loss of target } \\
\text { material. }\end{array}$ & $\begin{array}{l}\text { Low consumption of sample, sorbent, and } \\
\text { organic solvents; cheapness; accessible tools; } \\
\text { simplicity of handing; fast automation. }\end{array}$ & $\begin{array}{l}\text { Blocking pipe-tip; leakage of sorbent; } \\
\text { incompatible with solid samples. }\end{array}$ \\
\hline
\end{tabular}

Figure 1. As seen, conventional SPE is the most frequently used (54\%), followed by MSPE and DSPE at 22 and 11\%, respectively, and the two modes of SPME and MSPD are not higher than 10\%, while PT-SPE and SBSE are both just $1 \%$. The main characteristics, advantages, and disadvantages of the seven types of SPE techniques are listed in Table 1, with a reasonable expansion and modification of Figure 1 of our previous work (Arabi et al., 2020).

\section{EMERGING TECHNIQUES FOR MIPS PREPARATION}

Various efficient MIPs toward antibiotics have been prepared by virtue of emerging techniques such as surface imprinting, nanoimprinting, and living/controlled radical polymerization (LCRP) technology and multitemplate, multifunctional monomer, and dummy template imprinting strategy. Figure 2 schematically illustrates the six techniques' basic processes/mechanisms.

\section{Surface Imprinting}

Surface imprinting technology means preparing imprinted materials by controlling templates to locate at the surface or in the proximity of materials surface to create more effective recognition sites (Chen et al., 2016). It can overcome the disadvantages of low binding capacity and difficulty in elution of traditional MIPs. Core-shell structured MIPs are the major type of surface imprinting MIPs, owing to the increased surface area and larger binding capacity, and thus, they are widely used 


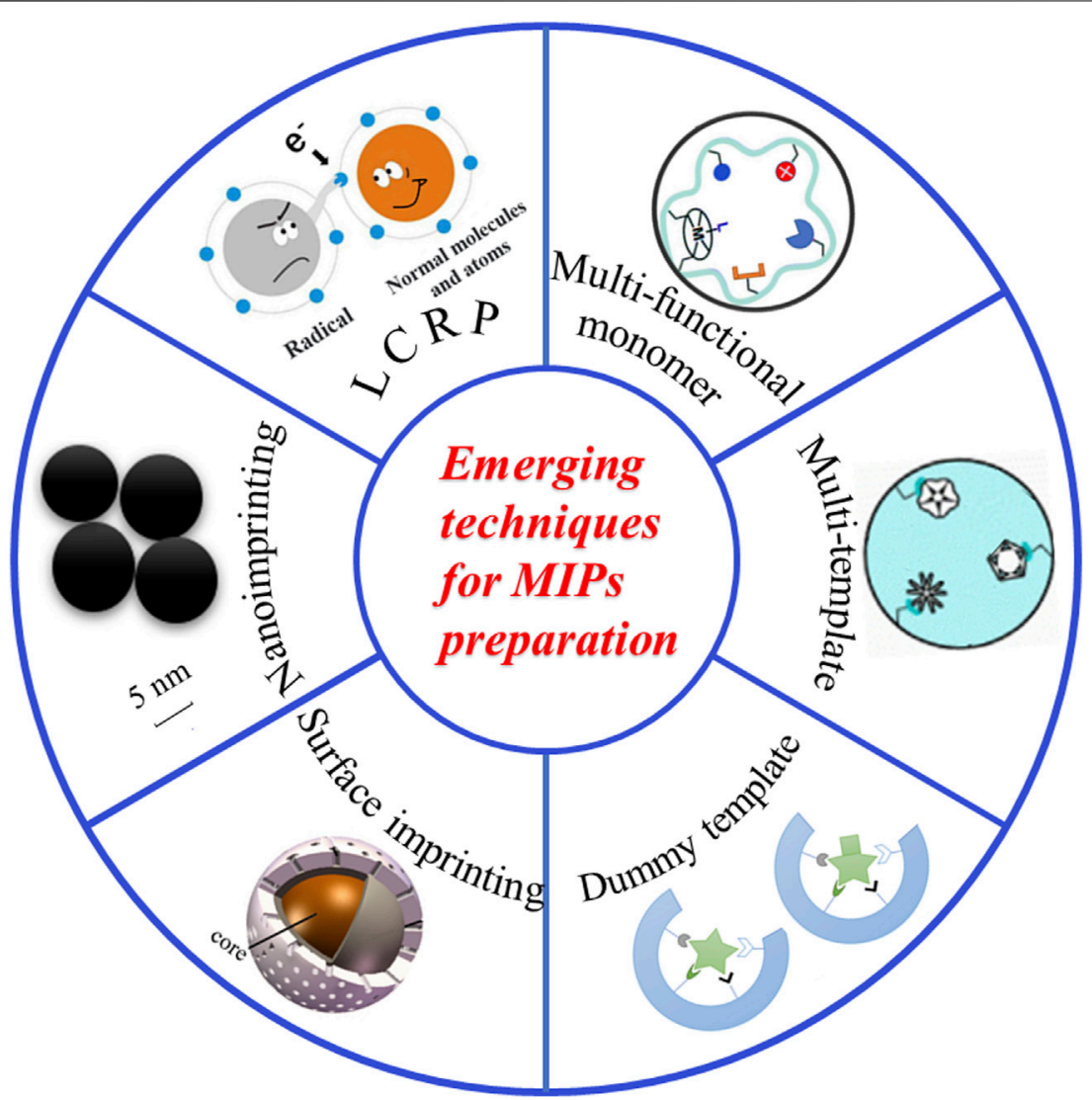

FIGURE 2 | Schematic diagram of the emerging typical techniques for MIPs preparation.

for detecting antibiotic residues (Ji et al., 2018; Liu et al., 2018; Negarian et al., 2019; Qin et al., 2019; Zhu et al., 2019a).

\section{Nanoimprinting}

Nanoimprinting technology is the technique of preparing nanosized MIPs. Nanomaterials have a large surface area and more binding sites, which can effectively improve the binding capacity of MIPs. To a certain extent, the problems of fewer target sites and low mass transfer rate of large-size MIPs are solved. Moreover, the nanostructured MIPs can be directly used without grinding, simplifying the experimental operation. The commonly used methods to synthesize nano-MIPs microspheres include precipitation polymerization (Liu et al., 2018), sol-gel (Li G. et al., 2018; Diaz-Alvarez et al., 2019), and core-shell polymerization (Qin et al., 2019). Nanoimprinting technology can be divided into zero-dimensional, one-dimensional, and two-dimensional types (Li and Wang, 2020).

\section{LCRP}

LCRP overcomes the disadvantage that the growth rate of the traditional radical polymerization chain is not easy to control and causes the particle size distribution of the polymer to be in a narrow range. Among them, atom transfer radical polymerization (ATRP) and reversible addition-fragmentation chain transfer (RAFT) polymerization are the most commonly used ones.
LCRP technology has been increasingly used for the determination of antibiotic residues (Liang Y. et al., 2018; Zhao et al., 2018; Cai et al., 2019; Li et al., 2020b; Cai et al., 2021) and other environmental contaminants (Azizi et al., 2020).

\section{Multitemplate Imprinting}

Multitemplate imprinting strategy means that two or more targeted analytes are as templates to prepare MIPs and thereby there are multiple recognition sites of template molecules in one imprinted polymer material (Wang et al., 2019). Due to the expansion of binding sites and recognition ability of MIPs, simultaneous recognition, enrichment, and separation of multiple targets can be realized, which greatly saves time and improves the utilization efficiency of MIPs. It has great potential in multiresidue and high-throughput analysis of complex samples (Wei et al., 2016; Xu et al., 2018; Lu et al., 2019; Dil et al., 2021).

\section{Multifunctional Monomer Imprinting}

The multifunctional monomer imprinting strategy is to take advantage of two or more functional monomers to interact with template molecules; by giving full play the synergistic effects of multiple functional monomers, MIPs selectivity is significantly enhanced and thereby enrichment ability. The strategy has been increasingly applied in antibiotics determination (Li G. et al., 2018; Li Z. et al., 2018; Cai et al., 2021). 


\section{Dummy Template Imprinting}

Dummy template imprinting strategy is also called pseudotemplate imprinting strategy, which uses similar compounds to the target compounds as a template in the shape, size, structure, and functionality. It is a high requirement and especially suitable for the target compounds that are costly, flammable, explosive, easy to degrade, and having too low solubility. The strategy can effectively avoid template leakage pollution or inaccurate results. The most common method is the computer-aided design of dummy template toward MIPs (Song et al., 2017). MISPE prepared by dummy template imprinting strategy is widely used in the detection of antibiotic residues (Song et al., 2019; Zhang Z. et al., 2020; Gao et al., 2021).

\section{APPLICATIONS OF MISPE TO ANALYSIS OF ANTIBIOTICS RESIDUES}

The wide applications of MISPE to the analysis of antibiotics residues are summarized, including SAs, QNs, TCs, and other antibiotics. Some typical examples are listed in Table 2.

\section{SAs}

SAs residues are closely related to food and environmental safety levels. The pollution sources of SAs antibiotics mainly include medical sources (patients feces and urine, antibiotics remaining on medical supplies, losses in the production of antibiotics by pharmaceutical enterprises, etc.), animal sources (animal excrement and urine, leakage of sewage from farms, etc.), and aquaculture (overuse of antibiotics in the process of farming, etc.) (Zhang Y. et al., 2020). The key to detection is to develop fast, efficient, and highly selective pretreatment methods. Common SPE materials for SAs include HLB, C18, and Oasis MCX which are relatively general and commercially available, but they lack selectivity for SAs. MISPE can identify, extract, and enrich the target substances with high selectivity and specificity and has high adsorption capacity and stability. At the same time, various SPE devices have become smaller and are easier to operate. MISPE has been widely used coupled with chromatographic determination toward SAs in complex samples (Wang J. et al., 2018; Fonte et al., 2018; Huang et al., 2018; Kechagia et al., 2018; Xu et al., 2018; Zhao et al., 2018; Zhu et al., 2019a; Zhu et al., 2019c; Gao et al., 2021; Zhao et al., 2021).

In order to improve the selective adsorption performance of MIPs in strong polar solvents, Zhu et al. (2019a) synthesized sulfamethoxazole (SMZ) imprinted polymers in methanol by using a new ionic liquid (IL) functional monomer, namely, 1butyl-3-vinylbromidazole (BVIM-Br). The MIPs exhibited highly specific recognition properties toward the three commonly found SAs (SMZ, sulfamonomethoxine (SMM), and sulfadiazine (SDZ)) in methanol, while low adsorption ability was displayed for the interferents. Then, a MISPE methodology was developed and successfully applied to effective enrichment of trace SMZ in soil and sediment samples, followed by HPLC analysis. The limits of detection (LODs) were all as low as $5 \mu \mathrm{g} / \mathrm{L}$. The present research can offer an important reference for influential MIPs preparation in aqueous media. Furthermore, Zhu et al. (2019c) prepared SMM surface imprinted polymers in the strong polar solvent of methanol with 1-allyl-3-vinylimidazolium chloride (AVIM$\mathrm{Cl}$ ) IL as a functional monomer. The developed MISPE coupled with HPLC was established for the selective extraction and sensitive determination of trace SMM in soil and sediment samples. The recoveries were high to $95.0-105.0 \%$ and the LOD was low to $1.0 \mu \mathrm{g} / \mathrm{L}$. Such MIPs materials have a broad application prospect in the pretreatment of various complex samples.

Zhao et al. (2021) synthesized hydrophilic magnetic MIPs (HMMIPs) on the surface of silanated $\mathrm{Fe}_{3} \mathrm{O}_{4}$ via surface imprinting technique and using SDZ as a template molecule and employed them as DSPE adsorbents for the enrichment and purification of 10 SAs prior to HPLC-UV detection in chicken, cow milk, and goat milk samples. Under the optimal experimental conditions, good linearity in the range of $5 \mu \mathrm{g} / \mathrm{L}$ to $10 \mathrm{mg} / \mathrm{L}$ was exhibited, low LODs ranged from 0.57 to $1.50 \mu \mathrm{g} / \mathrm{L}$, and high spiked recoveries were between 85.09 and $110.93 \%$. The HMMIPs-DSPE method can provide a potentially applicable way for the sensitive, reliable, simple, and rapid detection of various drug residues. In the previous work (Zhao et al., 2018), water-compatible MIPs were also prepared by combining RAFT with reflux precipitation polymerization (RPP), and the resulting MISPE coupled with HPLC-MS/MS succeeded in the enrichment and determination of six SAs in animal-derived foods and water samples.

Gao et al. (2021) fabricated magnetic carbon nanotube dummy MIP (MCNTMIP) nanocomposite by surface imprinting technique and used it as MSPE adsorbent to realize the simultaneous separation and enrichment of 13 SAs (SDZ, sulfathiazole (ST), sulfamerazine (SM1), sulfamethazine (SM2), sulfamethizole (SMZO), SMM, sulfachloropyridazine (SCP), sulfadoxine (SO), SMZ, sulfisoxazole (SFZ), and sulfaquinoxaline (SOX), sulfadimethoxine (SDM), and avermectin B1a) in fish and shrimp samples. Figure 3 illustrates the process of MIPs preparation and MSPE application. The MCNTMIP displayed a simple magnetic separation, specific molecular recognition, and high adsorption capacity. Coupled with ultra-high-performance liquid chromatography-tandem mass spectrometry (UPLC-MS/MS) determination of all the SAs, the LODs were all as low as $0.1 \mu \mathrm{g} / \mathrm{kg}$, and the recoveries were in a range of $90.2-99.9 \%$. Moreover, the precision values ranged from 0.5 to $9.1 \%$. Consequently, the developed MCNTMIP-MSPE method can be routinely utilized for the trace analysis of SAs to ensure food quality and consumer safety.

\section{QNs}

QNs are a class of antibacterial drugs with 1,4-dihydro-4oxyquinoline-3-carboxylic acid structure. They are widely used in clinical diagnosis and treatment, animal disease prevention, and growth promotion because of their advantages such as wide antibacterial spectrum, good efficacy, small toxic and side effects, simple synthesis, and low cost. The residual concentration of QNs is low, mostly ng/L or ng $/ \mathrm{kg}$. Excessive or improper use of QNs in animal-derived food has potential carcinogenic, teratogenic, and 
TABLE 2 | Applications of MIPs for SPE of antibiotics coupled with chromatographic determination.

\begin{tabular}{|c|c|c|c|c|c|c|c|c|c|}
\hline SPE mode & Analyte & Template & MIPs preparation technique & $\begin{array}{c}\text { Functional } \\
\text { monomer }\end{array}$ & Cross-linker & Real sample & $\begin{array}{l}\text { Detection } \\
\text { technique }\end{array}$ & LOD & Ref. \\
\hline \multirow{5}{*}{$\begin{array}{l}\text { (Conventional) } \\
\text { SPE }\end{array}$} & SAR & SAR & $\begin{array}{l}\text { ATRP } \\
\text { Dual-functional monomer }\end{array}$ & 4-VP-co-MAA & EGDMA & Egg & UPLC/MS-MS & $1.27 \mathrm{ng} / \mathrm{g}$ & Cai et al. (2021) \\
\hline & SMZ & SMZ & Surface imprinting & BVIM-Br & EDMA & $\begin{array}{l}\text { Cultivated soil, vegetable soil, } \\
\text { and sediment }\end{array}$ & HPLC & $0.005 \mathrm{mg} / \mathrm{L}$ & Zhu et al. (2019b) \\
\hline & $\begin{array}{l}\text { OFX, GAT, NOR, CIP, DIF, PEF, SAR, ENX, floxacin, } \\
\text { ENR, and LOM }\end{array}$ & - & - & - & - & Wastewater and sludge & UPLC/MS-MS & 6-150 ng/L & Yu et al., $2020^{\mathrm{a}}$ \\
\hline & NFX & NFX & Noncovalent surface imprinting & MAA & EGDMA & $\begin{array}{l}\text { Seawater } \\
\text { Marine and sediments }\end{array}$ & HPLC-DAD & $\begin{array}{l}2 \mu \mathrm{gg} / \mathrm{L} \\
5 \mu \mathrm{kg}\end{array}$ & Qin et al. (2020) \\
\hline & $\begin{array}{l}\text { TC, CTC, and DC } \\
\text { CIP and LEV }\end{array}$ & $\begin{array}{l}\text { TC, CTC, and DC } \\
\text { CIP and LEV }\end{array}$ & $\begin{array}{l}\text { In situ polymerization } \\
\text { Bulk polymerzation } \\
\text { Dual-template imprinting }\end{array}$ & $\begin{array}{l}\text { MMA } \\
{[\mathrm{C} 2 \mathrm{~min}][\mathrm{Br}]}\end{array}$ & $\begin{array}{l}\text { EDMA } \\
\text { EDMA }\end{array}$ & $\begin{array}{l}\text { Egg } \\
\text { Human urine }\end{array}$ & $\begin{array}{l}\text { HPLC -FLD } \\
\text { HPLC }\end{array}$ & $\begin{array}{l}3.0-5.5 \mu \mathrm{g} / \mathrm{kg} \\
0.06 \mathrm{and} \\
0.27 \mu \mathrm{g} / \mathrm{ml}\end{array}$ & $\begin{array}{l}\text { Huang L. et al. (2019) } \\
\text { Ma and Row (2019) }\end{array}$ \\
\hline \multirow[t]{2}{*}{ DSPE } & NOR and ENR & NOR and ENR & $\begin{array}{l}\text { Precipitation polymerization } \\
\text { Dual-template imprinting } \\
\text { Tap water }\end{array}$ & MAA & EGDMA & $\begin{array}{l}\text { Lake water } \\
\text { Seawater }\end{array}$ & HPLC & $\begin{array}{l}0.22 \text { and } \\
0.36 \mu g / L\end{array}$ & Lu et al. (2019) \\
\hline & $\begin{array}{l}\text { AZI, TYL, } \\
\text { SPM, TIL, ERY, CLA, and ROX }\end{array}$ & TUL & Precipitation polymerization & MAA & EGDMA & Pork & LC-MS/MS & $0.2-0.5 \mu \mathrm{g} / \mathrm{kg}$ & Song et al. (2018) \\
\hline \multirow[t]{4}{*}{ DSPE } & $\begin{array}{l}\text { SDZ, STZ, SMR, SM2, SMT, SMP, SCP, SMM, SIA, } \\
\text { and SDX }\end{array}$ & SM2 & Surface imprinting & MAA & HEMA & $\begin{array}{l}\text { Chicken } \\
\text { Cow milk } \\
\text { Goat milk }\end{array}$ & HPLC & $0.57-1.50 \mu \mathrm{g} / \mathrm{L}$ & Zhao et al. (2021) \\
\hline & AZI, SPM, TLL, TYL, CLA, ROX, and JOS & SPM & Surface imprinting & MAA & EDMA & Honey & HPLC-MS/MS & $3-17 \mathrm{ng} / \mathrm{kg}$ & Ji et al. (2018) \\
\hline & TC, OT, CTC, and DC & TC & Precipitation polymerization ${ }^{(a)}$ & MAA & EGDMA & Milk & LVSS-CE & - & Aguilar et al., 2020 \\
\hline & OFX, PEF, NOR, ENR, and GAT & OFL & RAFT & MAA & EGDMA & $\begin{array}{l}\text { Milk } \\
\text { River water }\end{array}$ & HPLC-UV & $\begin{array}{c}1.02-3.15 \\
0.93-2.87 \mu g / L\end{array}$ & Li et al. (2020b) \\
\hline \multirow[t]{4}{*}{ MSPE } & $\begin{array}{l}\text { SDZ, STZ, SMR, SM2, SMM, SCP, SO, SMZ, SFZ, } \\
\text { SOX, SDM, and avermectin B1a }\end{array}$ & Sulfabenzamide & $\begin{array}{l}\text { Surface imprinting } \\
\text { Dummy template }\end{array}$ & MAA & EGDMA & Fish and shrimp & UPLC-MS/MS & $0.1 \mu \mathrm{g} / \mathrm{kg}$ & Gao et al. (2021) \\
\hline & CAP & CAP & $\begin{array}{l}\text { Microwave-heating induced } \\
\text { polymerization (b) } \\
\text { Surface imprinting }\end{array}$ & $4-\mathrm{VP}$ & TRIM & Chicken feed & UPLC-MS/MS & $0.12 \mathrm{mg} / \mathrm{kg}$ & $\begin{array}{l}\text { Kunsa-Ngiem et al. } \\
\text { (2018) }\end{array}$ \\
\hline & CAP & CAP & $\begin{array}{l}\text { Suspension polymerization } \\
\text { Dual-functional monomer } \\
\text { imprinting }\end{array}$ & $\begin{array}{l}\text { MAA } \\
\text { and/or AM }\end{array}$ & EGDMA & Pork and honey & HPLC-UV & $10 \mu \mathrm{g} / \mathrm{L}$ & Li Z. et al. (2018) \\
\hline & CAP & CAP & Surface imprinting & MAA & EGDMA & Marine sediments & HPLC-DAD & $0.1 \mu \mathrm{g} / \mathrm{L}$ & Qin et al. (2019) \\
\hline TC and OT & TC & $\begin{array}{l}\text { Pickering emulsion } \\
\text { polymerization }\end{array}$ & MAA & DVB & $\begin{array}{l}\text { Fish, chicken, and } \\
\text { tap water }\end{array}$ & HPLC & 1.42 and $1.58 \mu \mathrm{g} / \mathrm{L}$ & & Ma et al. (2020) \\
\hline PZQ enantiomers & PZQ & $\begin{array}{l}\text { Surface imprinting } \\
\text { Nanoimprinting }\end{array}$ & Py & - & Sheep milk & HPLC-DAD & $0.01 \mu \mathrm{g} / \mathrm{ml}$ & & $\begin{array}{l}\text { Nascimento et al. } \\
\text { (2020) }\end{array}$ \\
\hline $\mathrm{TC}, \mathrm{OT}$, and CTC & TC & $\begin{array}{l}\text { Nanoimprinting } \\
\text { Surface imprinting }\end{array}$ & APBA & APBA & Milk powder & UPLC-MS/MS & $\begin{array}{l}0.278,0.318, \text { and } \\
0.217 \mathrm{ng} / \mathrm{g}\end{array}$ & & Wang S. et al. (2018) \\
\hline \multirow[t]{2}{*}{ SPME } & DAN, NOR, ENR, and CIP & ENR & - & MAA & EGDMA & $\begin{array}{l}\text { Surface water, groundwater, } \\
\text { and urine }\end{array}$ & HPLC-MS/MS & $0.1-10 \mu \mathrm{g} / \mathrm{L}$ & $\begin{array}{l}\text { Barahona et al. } \\
\text { (2019) }\end{array}$ \\
\hline & ERY, CLA, AZI, LEU, and ROX & ROX & Surface imprinting & MAA & EGDMA & Drinking water, honey, and milk & ESI-MS & $\begin{array}{l}0.003-0.05 \\
1.1-5.1 \\
1.9-15.8 \mathrm{ng} / \mathrm{g}\end{array}$ & Liu et al. (2019) \\
\hline SBSE & SDZ, SMD, SMM, and SDM & SMM & Emulsion polymerization & MAA & EGDMA & $\begin{array}{l}\text { Regular chicken feed, } \\
\text { and pig feed } \\
\text { Suckling pig feed } \\
\text { Two types of laying-hen feeds }\end{array}$ & HPLC-MS/MS & $1.5-3.4 \mu \mathrm{g} / \mathrm{L}$ & Cui et al. (2021) \\
\hline \multirow[t]{3}{*}{ PT-SPE } & $\begin{array}{l}\text { CIP and ENR } \\
\text { MARBO and NOR }\end{array}$ & ENR & Thermal radical polymerization ${ }^{(d)}$ & MAA & EGDMA & Human urine & HPLC-DAD & $18 \mathrm{ng} / \mathrm{ml}$ & $\begin{array}{l}\text { de Oliveira et al. } \\
\text { (2016) }\end{array}$ \\
\hline & $\begin{array}{l}\text { ABA and EPR } \\
\text { MOX }\end{array}$ & ABA & - & $1-\mathrm{Vl}$ & TRIM & Mineral water grape juice & HPLC-UV & - & Teixeira et al. (2018) \\
\hline & CIP & CIP & In situ polymerization & MAA & EGDMA & $\begin{array}{l}\text { Seawater and human blood } \\
\text { plasma tablet }\end{array}$ & Spectrophotometry & $1.50 \mu \mathrm{gg} / \mathrm{L}$ & Hashemi et all, 2019 \\
\hline
\end{tabular}

AM, acrylamide; APBA, 3-aminophenylboronic acid; AZI, azithromycin; CLA, clarithromycin; (C2min)(Br): 1-vinyl-3-ethylimidazolium bromide; DAN, danofloxacin; DIF, difloxacin; DVB, divinylbenzene; EDMA, ethylene dimethacrylate; EGDMA, ethylene glycol dimethacrylate; ERY, erythromycin; LEU, leucomycin; LEV, levofloxacin; HEMA, hydroxyethyl methylacrylate; IVM, ivermectin; Py, pyrrole; ROX, roxithromycin; SDX, sulfameter; SIA, sulfisoxazole; SMP, sulfamethoxypyridazine; SMD, sulfameter; SMT, sulfamethoxydiazine; MAA, methacrylic acid; MMA, methyl methacrylate; SPM, spiramycin; TLL, tilmicosin; TYL, tylosin; 4-VP, 4-vinyl pyridine.

(a) Persulfate; (b) 1,1-azobis(cyclohexanecarbonitrile) (ABCN); (c) 0.1 mol/LNa2S2O8 $(6.5 \mathrm{ml}$ ) aqueous solution; (d) 4,4'-azobis(4-cyanovaleric acid), four different initiators; the other initiators were AlBN.

${ }^{a}$ MIP-SPE cartridges (SupelMIP) were obtained from Sigma-Aldrich (Shanghai, China). 


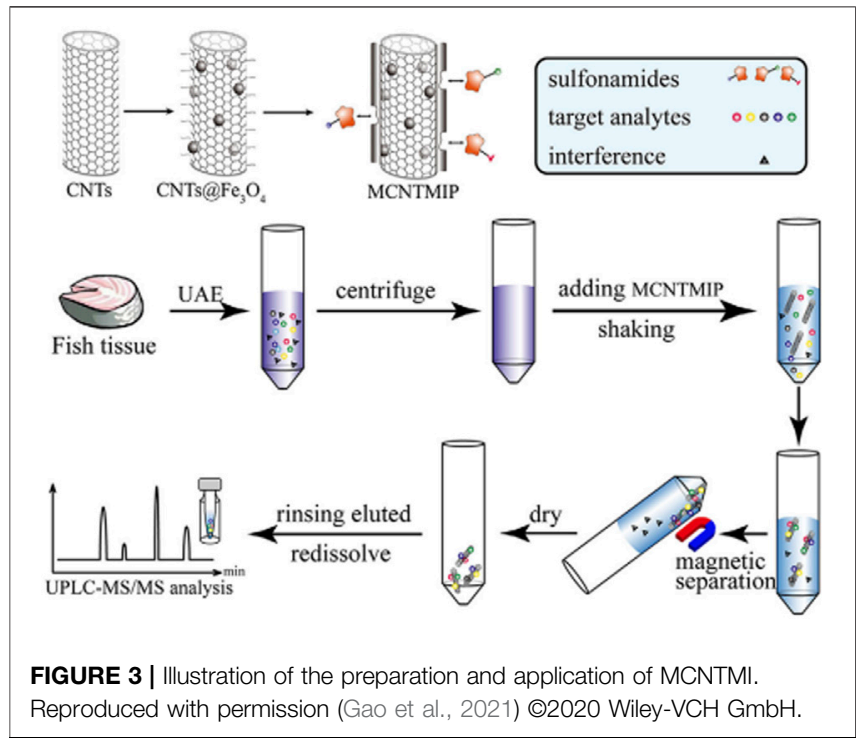

mutagenic effects, thus threatening human health. Almost all countries have formulated the maximum residual limit standard (MRLS) for quinolone antibiotics. MISPE is widely used in the determination of QNs in complex substrates (Li G. et al., 2018; Wang J. et al., 2018; Hu et al., 2018; Rodriguez-Gomez et al., 2018; Barahona et al., 2019; Zhu et al., 2019b; Ma and Row, 2019; Li et al., 2020b; Tian et al., 2020; Yu et al., 2020; Cai et al., 2021; Soares et al., 2021).

Our group (Lu et al., 2019) prepared novel double-template MIPs (dt-MIPs) via a simple and facile precipitation polymerization method with norfloxacin (NOR) and enrofloxacin (ENR) as templates and used them in DSPE combined with HPLC-DAD for the simultaneous selective enrichment and determination of two fluoroquinolones (FQs) in environmental water samples. Figure 4 schematically shows the dt-MIPs preparation and DSPE process. The well-prepared dt-MIPs exhibited good adsorption capacity and selectivity for NOR and ENR, with high enrichment factors of 71 and 61 , respectively. Good linearity was obtained in the range of $1-200 \mu \mathrm{g} / \mathrm{L}$. The LOD and limit of quantification (LOQ) values for NOR were 0.22 and $0.67 \mu \mathrm{g} / \mathrm{L}$, respectively, and 0.36 and $0.98 \mu \mathrm{g} /$ L for ENR. Satisfactory recoveries of the two FQs were attained of 80.9-101.0\% with relative standard deviations (RSDs) of 0.9-6.9\% from spiked lake, sea, and tap water samples. This study not only offered a good method choice for FQs detection but also enriched the research connotation of multitemplate imprinting.

Yu et al. (2020) developed a MISPE method for the simultaneous enrichment of 11 FQs [ofloxacin (OFX), gatifloxacin (GAT), NOR, ciprofloxacin (CIP), difloxacin, pefloxacin (PEF), sarafloxacin (SAR), enoxacin (ENX), floxacin, ENR, and lomefloxacin (LOM)] in water by UPLC/ MS-MS determination. The attained LODs of FQs were within 6-150 ng/L. The recoveries of all the targeted FQs in sample matrices were higher than 75\%, and RSDs were below 15\%. The developed MISPE-UPLC/MS-MS proved to be effective for the determination of FQs in wastewater and sludge samples.

Li et al. (2020b) successfully prepared restricted-access mediaimprinted nanomaterials (RAM-MIPs) on the surface of the metal-organic framework (MOF) by RAFT. Figure 5 shows the synthesized route of the RAM-MIPs. Then, they were applied for the DSPE of five FQs (OFX, PEF, NOR, ENR, and GAT) in milk and river water samples prior to HPLC-UV detection. The method attained low LODs, namely, $1.02-3.15 \mu \mathrm{g} / \mathrm{L}$ for milk samples and $0.93-2.87 \mu \mathrm{g} / \mathrm{L}$ for river water samples, respectively, as well as satisfactory recoveries, namely, $80.7-103.5 \%$ and $85.1-105.9 \%$, respectively. In comparison with other materials, the RAM-MIP materials are significantly advantageous owing to their simple preparation conditions, uniform and controllable imprinting layer thickness, fast adsorption rate, and so on. The present study demonstrates that RAM-MIP (prepared with MOF as a matrix)-based SPE has broad prospects toward efficient extraction of trace FQs in complex samples.

Cai et al. (2021), using surface-initiated ATRP and sarafloxacin (SAR) as a template, constructed monodisperse RAM-MIPs, and three methods were adopted, as illustrated in Figure 6. The optimum synthesis method was to combine 4vinylpyridine (VP) and methacrylic acid (MAA) (1:3) as monomers and to select an 8:1:32:8 ratio of a template molecule, cross-linker, and restricted-access functional monomer. The RAM-MIPs showed a high IF (6.05) and the selectivity coefficients were $1.86-2.64$ between SAR and other FQs. The RAM-MIP-packed SPE showed higher enrichment ability toward SAR in a complex protein-containing solution than that of traditional MIP-packed one. As a result, the MISPE coupled with the HPLC-UV method achieved a low LOQ for SAR at $4.23 \mathrm{ng} / \mathrm{g}$ and the high mean recoveries within 94.0-101.3\%. The present study indicated a great application potential of the RAM-MIPs based SPE for trace analysis in complex samples. Furthermore, the proposed functional monomer ratio and rebinding method opened a new way for devising and synthesizing various MIPs.

de Oliveira et al. (2016) used ENRO as the template molecule to synthesize MIP1, adopted a multitemplate imprinting strategy (four studied FQs as the template molecules) to synthesize MIP2, and utilized it for the simultaneous PT-SPE of the four FQs (CIP, ENR, marbofloxacin (MARBO), and NOR) in human urine samples. By comparison, MIP1 proved a better adsorbent, and high extraction efficiency was obtained to ENRO (96.0\%). Figure 7 schematically shows the apparatus employed for PTMIP- $\mu$-SPE. It was possible to extract CIPRO ( $40 \%)$, NOR $(\sim 40 \%)$, and MARBO $(\sim 80 \%)$ due to the similarity of the molecular structures. The method attained good linearity from 39 to $1,260 \mathrm{ng} / \mathrm{ml}$ for individual FQ, and the LOQ for individual FQ was as low as $39 \mathrm{ng} / \mathrm{ml}$. Finally, the validated PT-MIP- $\mu$-SPE method was proved to be practically applicable, through the preliminary cumulative urinary excretion study after administrating CIPRO to a healthy volunteer.

\section{TCs}

TCs, as a kind of broad-spectrum antibiotics produced by Streptomyces, have caused serious harm to the ecological environment and human health because of their wide use and hence residues. Huang L. et al. (2019) used TC, chlortetracycline (CTC), and doxycycline (DC) as the templates and magnetic graphene oxide $\left(\mathrm{Fe}_{3} \mathrm{O}_{4} / \mathrm{GO}\right)$ as the supporting material to prepare 
A
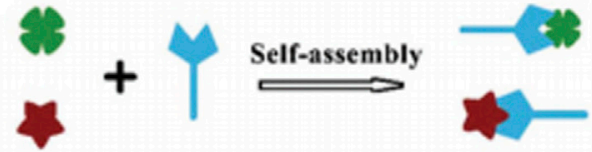

EGDMA

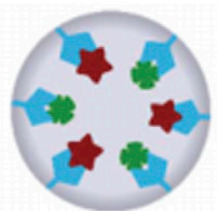

Removal

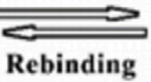

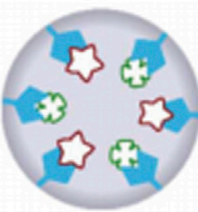

Templates MAA

dt-MIPs

B

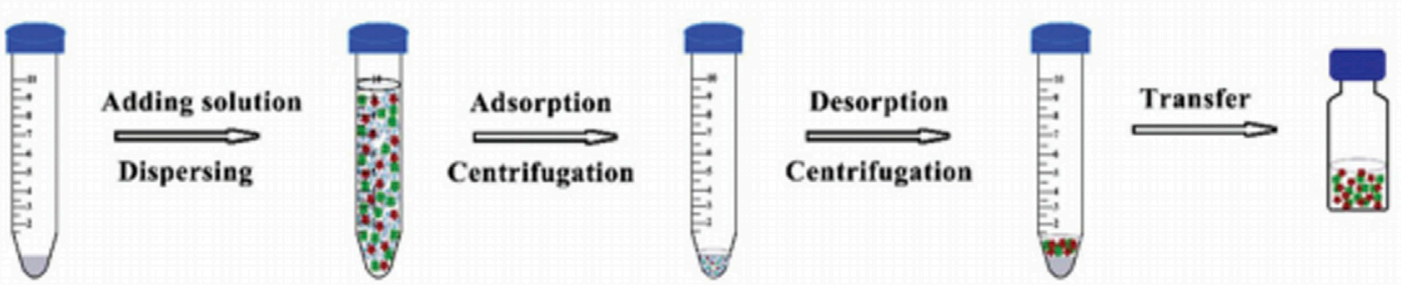

FIGURE 4 | Schematic for the procedures of dt-MIPs preparation by precipitation polymerization (A) and dt-MIPs-DSPE (B). Reproduced with permission (Lu et al., 2019) (The Royal Society of Chemistry 2019.

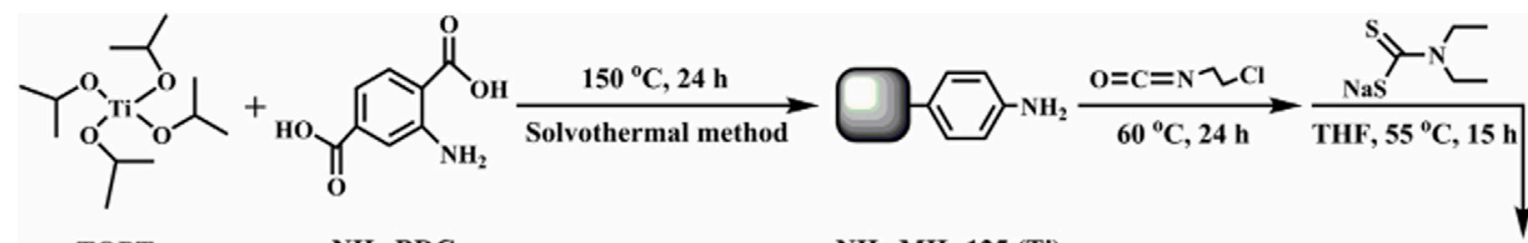

TOPT

$\mathrm{NH}_{2}-\mathrm{BDC}$

$\mathrm{NH}_{2}$-MIL-125 (Ti)
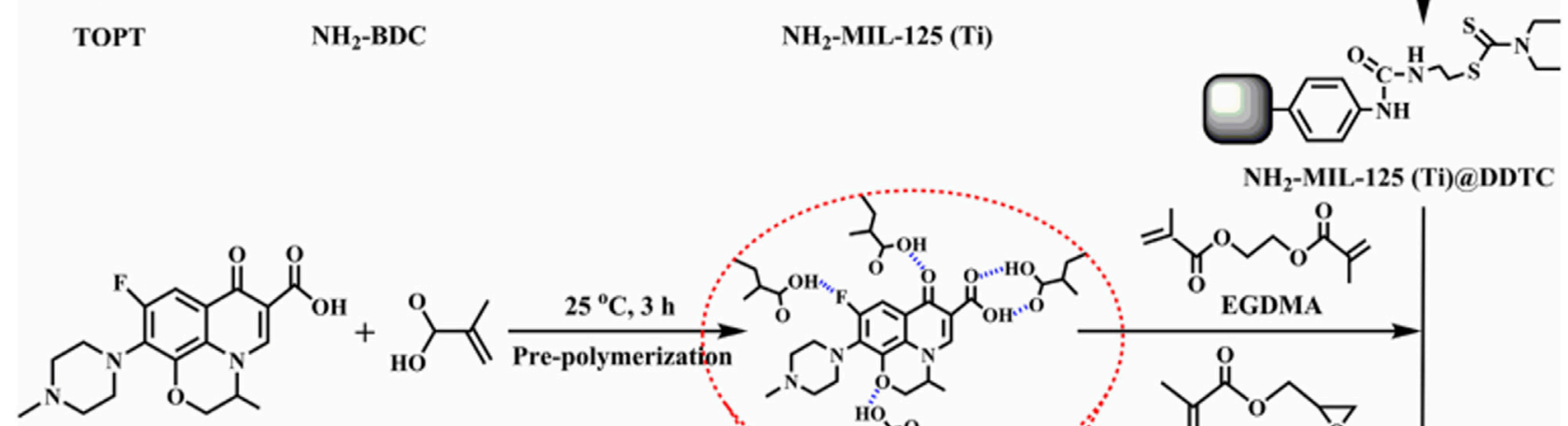

Template OFL

max<smiles>C=C(C)C(=O)O</smiles>

Pre-polymerization

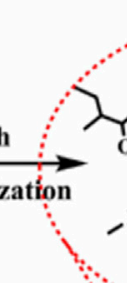

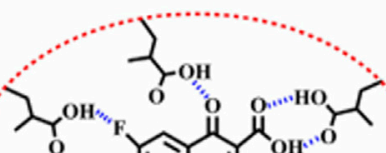

$\mathrm{NH}_{2}$-MIL-125 (Ti)@DDTC
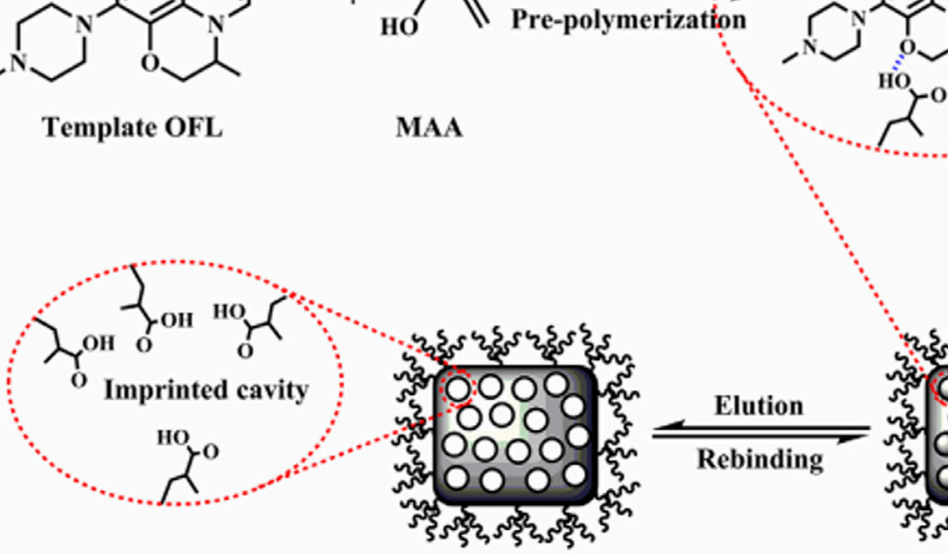

$\gamma^{0}$

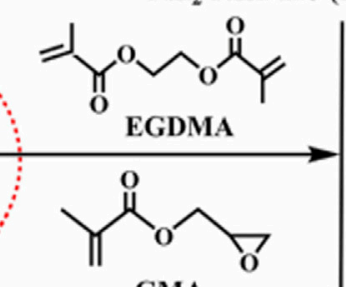

GMA

FIGURE 5 | The synthesized route of RAM-MIPs. Reproduced with permission (Li et al., 2020b) @2020 Elsevier B.V.

magnetic multi-MIPs. Then chip-based magnetic multi-MIPs monolithic capillary array columns were constructed for simultaneous MSPE and determination of the TCs in eggs samples. High affinity and specificity to TC, CTC, and DC were shown and the IFs reached 86-104-fold. The LOD values ranged from 3.0 to $5.5 \mu \mathrm{g} / \mathrm{kg}$. Therefore, the MISPE columns 


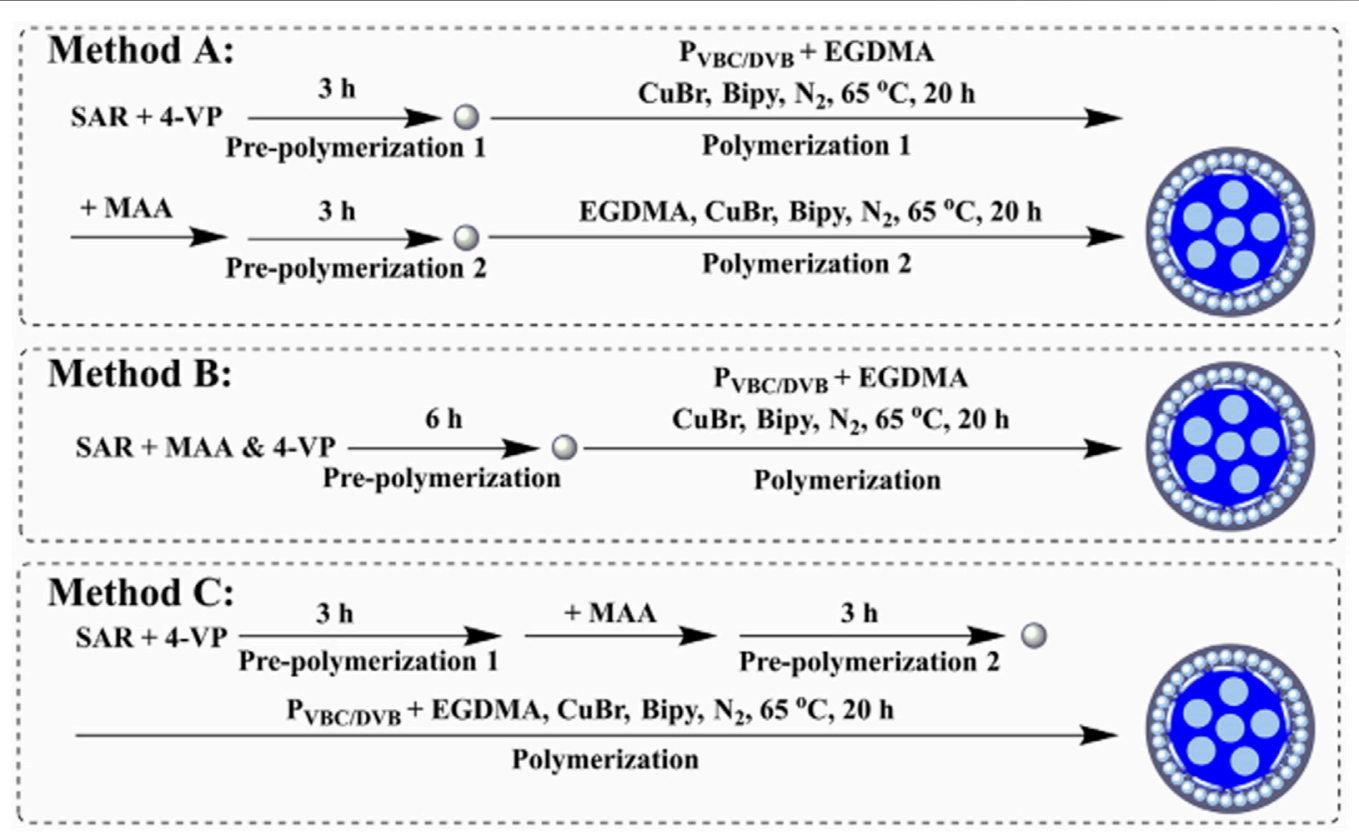

FIGURE 6 | Three methods for preparing MIP microspheres. Reproduced with permission (Cai et al., 2021) @)2021 Elsevier B.V.

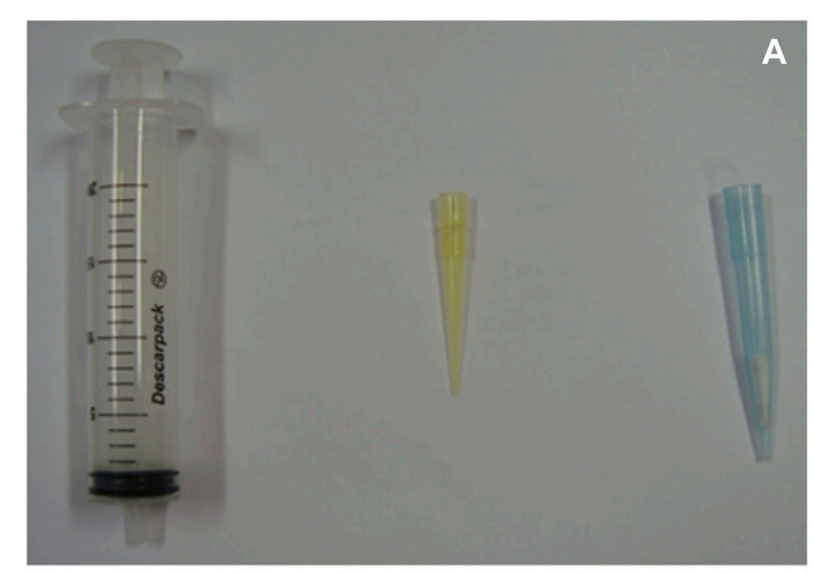

B

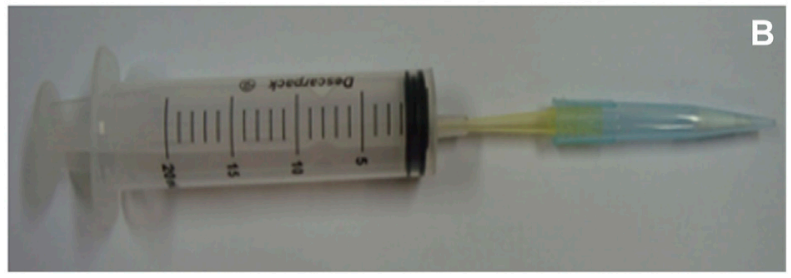

FIGURE 7|Apparatus employed for PT-MIP- $\mu$-SPE. (A) Components of the apparatus and $\mathbf{( B )}$ apparatus mounted. Reproduced with permission (de Oliveira et al., 2016) (C2016 Elsevier B.V.

afforded hopeful perspectives for the facile extraction of antibiotics from complicated samples.

Aguilar et al. (2020) synthesized the MIPs by precipitation polymerization using TC as template molecule and applied them for dispersive SPME (DSPME) and removal of TC residues in milk samples. The molecular recognition properties and selectivity of MIPs against four TCs (TC, oxytetracycline (OT), CTC and DC) were evaluated, and then high selectivity was demonstrated for the four TCs. The MIP-based DSPME process provided a high removal ratio between 81.83 and $96.44 \%$ with $\mathrm{RSD}<5 \%$ in all cases. Compared to classical removal methods, the present method was faster and required lower solvent consumption and minimum sample manipulation. Therefore, a promising prospect can be expected for facilely synthesizing efficient and selective adsorbents and utilizing MISPE for the simultaneous removal of multiple contaminants residues.

Ma et al. (2020) prepared magnetic molecularly imprinted biochar microspheres with specific adsorption of TCs (TC; OT) by Pickering emulsion polymerization. The obtained materials were employed as adsorbents for extraction and purification of TCs in actual samples (fish, chicken, and tap water). This method was simple in preparation process and cost-effective; the synthesized polymer was a regular spherical structure with magnetic response characteristics, which can simplify the extraction and purification of sample pretreatment. It offers a new idea for the application of MIPs based biochar in contaminant detection in food samples.

\section{Other Antibiotics}

CAP is a kind of broad-spectrum antibiotics isolated from Streptomyces venezuelae. Because its long-term and high dose use easily caused granulocytosis, aplastic anemia, and other diseases, China has banned its use in feed-animals (especially laying hens and dairy cows) and required CAPs residues to be mandatory test items in all aquatic products, livestock, and poultry products (Zhang et al., 2021). BLAs are a broad class of antibiotics, 
and their residues mainly come from agricultural and veterinary drugs, medical drugs, and wastewater treatment discharges from sewage plants. They pose potential threats to the human body and ecology. For example, a few patients will have allergic reactions to BLAs, and the residual antibiotics in the soil will affect the growth of plant roots and seed germination, etc. In addition, the pollution of Antibiotic-Resistant Bacteria (ARB) and Antibiotics Resistance Gene (ARG) caused by the abuse of BLAs and other antibiotics is threatening human health and ecological safety (Li et al., 2020a). MALs are widely used in clinical and veterinary medicine fields, with a broad spectrum of antimicrobial effects, especially for animal husbandry and aquaculture (Liang and Zhang, 2021). At present, more and more efforts have been devoted to the monitoring of MALs residues.

Using MISPE technology with excellent performance, the trace detection of various antibiotics in diverse complex substrates has been realized (Li Z. et al., 2018; Lian and Wang, 2018; Xie et al., 2018; Negarian et al., 2019; Qin et al., 2019; Garza Montelongo et al., 2020; Tan et al., 2020). For example, Qin et al. (2019) developed a straightforward method for selective separation of CAP from marine sediment samples. CAPMMIPs were synthesized via surface imprinting and nanoimprinting technologies. The material has a perfect coreshell structure, excellent thermal stability, and high selectivity toward CAP. The CAP-MMIPs were employed for fast and selective SPE of CAP followed by HPLC-DAD. An excellent linearity was attained from 0.1 to $20 \mathrm{mg} / \mathrm{L}\left(\mathrm{R}^{2}=0.999, n=3\right)$, and the LOD was $0.1 \mu \mathrm{g} / \mathrm{L}$. The spiked recoveries were between 77.9 and $102.5 \%$ with low RSDs $(<6.3 \%)$. Good reusability was achieved (at least 5 times) by the regeneration and there was hardly any loss of selectivity and adsorption capability. Such MMIPs-SPE method can provide a vital alternate to traditional extraction ones for preparing environmental samples.

Teixeira et al. (2018) prepared 1-vinylimidazole-cotrimethylolpropane trimethacrylate- (1-VI-co-TRIM-) based MIPs adsorbent for PT-SPE of abamectin (ABA), eprinomectin (EPR), and moxidectin (MOX), coupled to HPLC-UV determination. The performance criteria for linearity, sensitivity, precision, accuracy, recovery, robustness, and stability were systematically assessed and were within the recommended guidelines. The validated PT-MIP-SPE proved to be economical, simple, easy-to-perform, and potentially applicable for the extraction of MALs in complicated samples.

Nascimento et al. (2020) firstly synthesized a new selective adsorbent based on magnetic molecularly imprinted polypyrroleconducting polymer (MMIPPy) and applied it to the MSPE of praziquantel (PZQ) enantiomers [(R)-(-)-PZQ and (S)(+)-PZQ] combined with HPLC-DAD determination. Under optimal conditions, excellent linearity was attained in a range of $0.01-10 \mu \mathrm{g} / \mathrm{ml}$, with correlation coefficients higher than 0.98 and RSDs less than $15 \%$. The LOQ was $0.01 \mu \mathrm{g} / \mathrm{ml}$ for both enantiomers, and RSDs and relative errors were below 20\%. The method was applied satisfactorily for the determination of PZQ enantiomers from sheep milk samples with the possibility to other analytes in different complex matrices. The economical, simple, and easy-to-perform MMIPPy-MSPE method suggested great application potential for antibiotics residues determination.

\section{CONCLUSIONS AND PROSPECTS}

To summarize, we review recent advances on both the classification of MISPE and new imprinting techniques for antibiotics coupled with chromatographic analysis, with emphasis on typical examples of MISPE in SAs, QNs, TCs, and other antibiotics. The use of emerging typical imprinting techniques has greatly improved the performance of MISPE and further broadened its application scope. The advancement of new imprinting techniques, especially the combination of multiple techniques, can effectively solve some problems in the practical application of traditional MIPs, such as low binding capacity, template leakage, and difficulties in aqueous phase identification, and provide a better performance, easier separation, and intelligently controlled release of MIPs as solidphase sorbents. This can provide an effective means to eliminate matrix interference and enrich trace antibiotics with high selectivity. Moreover, the sample pretreatment will definitely develop in the direction of economical, efficient, environmentally friendly, and easy to operate related aspects. In order to further improve the extraction efficiency of MISPE by using ideal MIPs with greater adsorption capacity, higher selectivity, better hydrophilicity, and easier separation, it is necessary to introduce more and advanced preparation techniques, especially to explore the rational synergistic combination of multiple imprinting techniques. Furthermore, the large-scale production and commercialization of the wellprepared MIPs and well-established MISPE should be given more attention, in order to push forward their greater advance and wider applications.

\section{AUTHOR CONTRIBUTIONS}

DS: writing the original draft. ZS: supervision, revising the manuscript, and funding support. YZ: searching for references and writing part of the original draft. YW: reviewing the manuscript. ML: reviewing and revising the manuscript and funding support. HL: reviewing and revising the manuscript. LW: searching for reference and revising the manuscript. JL: supervision, revising the manuscript, and funding support. LC: editing the manuscript and funding support.

\section{FUNDING}

This work was financially supported by the National Natural Science Foundation of China (21876199, 22008128, 21976209), the Youth Innovation Promotion Association CAS (2021212), the Science and Technology Innovation Development Plan of Yantai City of China (2020MSGY112, 2020MSGY077), the Shandong Key Laboratory of Coastal Environmental Processes, YICCAS (2019SDHADKFJJ17), the National Demonstration Center for Experimental Pharmacy Education (Yantai University), the Natural Science Foundation of Shandong Province of China (ZR2020QB183, ZR2020KC032, ZR2020QC011), and the Taishan Scholar Project Special Funding (ts20190962). 


\section{REFERENCES}

Aguilar, J. F. F., Miranda, J. M., Rodriguez, J. A., Paez-Hernandez, M. E., and Ibarra, I. S. (2020). Selective Removal of Tetracycline Residue in Milk Samples Using a Molecularly Imprinted Polymer. J. Polym. Res. 27, 176. doi:10.1007/s10965-020-02139-9

Arabi, M., Ostovan, A., Bagheri, A. R., Guo, X., Wang, L., Li, J., et al. (2020). Strategies of Molecular Imprinting-Based Solid-phase Extraction Prior to Chromatographic Analysis. Trac Trends Anal. Chem. 128, 115923. doi:10.1016/j.trac.2020.115923

Arabi, M., Ostovan, A., Li, J., Wang, X., Zhang, Z., Choo, J., et al. (2021). Molecular Imprinting: Green Perspectives and Strategies. Adv. Mater. 2021, 2100543. doi:10.1002/adma.202100543

Azizi, A., Shahhoseini, F., and Bottaro, C. S. (2020). Magnetic Molecularly Imprinted Polymers Prepared by Reversible Addition Fragmentation Chain Transfer Polymerization for Dispersive Solid Phase Extraction of Polycyclic Aromatic Hydrocarbons in Water. J. Chromatogr. A. 1610, 460534. doi:10.1016/j.chroma.2019.460534

Balsebre, A., Báez, M. E., Martínez, J., and Fuentes, E. (2018). Matrix Solid-phase Dispersion Associated to Gas Chromatography for the Assessment in Honey Bee of a Group of Pesticides of Concern in the Apicultural Field. J. Chromatogr. A. 1567, 47-54. doi:10.1016/j.chroma.2018.06.062

Barahona, F., Albero, B., Tadeo, J. L., and Martín-Esteban, A. (2019). Molecularly Imprinted Polymer-Hollow Fiber Microextraction of Hydrophilic Fluoroquinolone Antibiotics in Environmental Waters and Urine Samples. J. Chromatogr. A. 1587, 42-49. doi:10.1016/j.chroma.2018.12.015

BelBruno, J. J. (2019). Molecularly Imprinted Polymers. Chem. Rev. 119, 94-119. doi:10.1021/acs.chemrev.8b00171

Cai, T., Ma, M., Liu, H., Li, J., Hou, J., and Gong, B. (2019). Preparation of Monodisperse Magnetic Surface Molecularly Imprinted Polymers for Selective Recognition of Lincomycin Hydrochloride in Milk. J. Liquid Chromatogr. Relat. Tech. 42, 459-467. doi:10.1080/10826076.2019.1625372

Cai, T., Zhou, Y., Liu, H., Li, J., Wang, X., Zhao, S., et al. (2021). Preparation of Monodisperse, Restricted-Access, Media-Molecularly Imprinted Polymers Using BiFunctional Monomers for Solid-Phase Extraction of Sarafloxacin From Complex Samples. J. Chromatogr. A. 1642, 462009. doi:10.1016/j.chroma.2021.462009

Chen, L., Wang, X., Lu, W., Wu, X., and Li, J. (2016). Molecular Imprinting: Perspectives and Applications. Chem. Soc. Rev. 45, 2137-2211. doi:10.1039/ c6cs00061d

Chen, Q., Bing, N., Xie, H., and Bao, Y. (2017). A Study on Antibiotics Pollution Status in Different Environment Media and Research Progress of Detection Methods. Environ. Monitor. Forewarn. 9, 24-31. doi:10.3969/j.issn.16746732.2017.05.007

Cui, Y., Jiang, L., Li, H., Meng, D., Li, H., Meng, D., et al. (2021). Molecularly Imprinted Electrospun Nanofibre Membrane Assisted Stir Bar Sorptive Extraction for Trace Analysis of Sulfonamides from Animal Feeds. J. Ind. Eng. Chem. 96, 382-389. doi:10.1016/j.jiec.2021.01.045

de Oliveira, H. L., da Silva Anacleto, S., da Silva, A. T. M., Pereira, A. C., de Souza Borges, W., Figueiredo, E. C., et al. (2016). Molecularly Imprinted Pipette-Tip Solid Phase Extraction for Selective Determination of Fluoroquinolones in Human Urine Using HPLC-DAD. J. Chromatogr. B. 1033-1034, 27-39. doi:10.1016/j.jchromb.2016.08.008

Díaz-Álvarez, M., Turiel, E., and Martín-Esteban, A. (2019). Molecularly Imprinted Polymer Monolith Containing Magnetic Nanoparticles for the Stir-Bar Sorptive Extraction of Thiabendazole and Carbendazim From Orange Samples. Analytica Chim. Acta. 1045, 117-122. doi:10.1016/ j.aca.2018.09.001

Dil, E. A., Ghaedi, M., Mehrabi, F., and Tayebi, L. (2021). Highly Selective Magnetic Dual Template Molecularly Imprinted Polymer for Simultaneous Enrichment of Sulfadiazine and Sulfathiazole From Milk Samples Based on Syringe-ToSyringe Magnetic Solid-Phase Microextraction. Talanta. 232, 122449. doi:10.1016/j.talanta.2021.122449

Dugheri, S., Marrubini, G., Mucci, N., Cappelli, G., Bonari, A., Pompilio, I., et al. (2021). A Review of Micro-Solid-Phase Extraction Techniques and Devices Applied in Sample Pretreatment Coupled With Chromatographic Analysis. Acta Chromatographica. 33, 99-111. doi:10.1556/1326.2020.00790

Fan, C. (2020). Applications of 3 New Solid Phase Extraction Technologies in Pretreatments of Food Analysis. J. Food Saf. Qual. 11, 4678-4684. doi:10.19812/ j.cnki.jfsq11-5956/ts.2020.14.029
Fleming, A. (1929). On the Antibacterial Action of Cultures of a Penicillium, with Special Reference to Their Use in the Isolation of B Influenzae. Br. J. Exp. Pathol. 10, 226-236. doi:10.1590/S0042-96862001000800017

Fonte, A. N. B., Castro, R., G., and Liva-Garrido, M. (2018). Multi-Residue Analysis of Sulfonamide Antibiotics in Honey Samples by On-Line Solid Phase Extraction Using Molecularly Imprinted Polymers Coupled to Liquid Chromatography-Tandem Mass Spectrometry. J. Liq. Chromatogr. Relat. Technol. 41, 881-891. doi:10.1080/10826076.2018.1533477

Gao, L., Qin, D., Chen, Z., Wu, S., Tang, S., and Wang, P. (2021). Determination of Sulfonamide Antibiotics in Fish and Shrimp Samples Based on Magnetic Carbon Nanotube Dummy Molecularly Imprinted Polymer Extraction Followed by UPLC-MS/MS. Electrophoresis. 42, 725-734. doi:10.1002/elps.202000243

Garza Montelongo, E., Sánchez Anguiano, M. G., Blanco Jerez, L. M., Pereira Ulloa, E. D., Rivas Quiroz, B. L., and Elizondo Martínez, P. (2020). Determination of Tylosin in Milk Samples by Poly(ethylene Terephthalate)-Based Molecularly Imprinted Polymer. J. Appl. Polym. Sci. 137, 49204. doi:10.1002/app.49204

Gaudin, V. (2020). The Growing Interest in Development of Innovative Optical Aptasensors for the Detection of Antimicrobial Residues in Food Products. Biosensors. 10, 21. doi:10.3390/bios10030021

Guo, X., Bai, H., Ma, X., Li, J., Ren, Y., Ouyang, Z., et al. (2020). Online Coupling of an Electrochemically Fabricated Solid-Phase Microextraction Probe and a Miniature Mass Spectrometer for Enrichment and Analysis of Chemical Contaminants in Infant Drinks. Analytica Chim. Acta. 1098, 66-74. doi:10.1016/j.aca.2019.11.021

Hammam, M. A., Abdel-Halim, M., Madbouly, A., Wagdy, H. A., and El Nashar, R. M. (2019). Computational Design of Molecularly Imprinted Polymer for Solid Phase Extraction of Moxifloxacin Hydrochloride from Avalox Tablets and Spiked Human Urine Samples. Microchemical J. 148, 51-56. doi:10.1016/ j.microc.2019.04.063

Hashemi, S. H., Ziyaadini, M., Kaykhaii, M., Jamali Keikha, A., and Naruie, N. (2019). Separation and Determination of Ciprofloxacin in Seawater, Human Blood Plasma and Tablet Samples Using Molecularly Imprinted Polymer Pipette-Tip Solid Phase Extraction and its Optimization by Response Surface Methodology. J. Sep. Sci. 43, 505-513. doi:10.1002/ jssc. 201900923

Haupt, K., Medina Rangel, P. X., and Bui, B. T. S. (2020). Molecularly Imprinted Polymers: Antibody Mimics for Bioimaging and Therapy. Chem. Rev. 120, 9554-9582. doi:10.1021/acs.chemrev.0c00428

Hu, Z.-H., Wang, Y. F., Omer, A. M., and Ouyang, X. k. (2018). Fabrication of Ofloxacin Imprinted Polymer on the Surface of Magnetic Carboxylated Cellulose Nanocrystals for Highly Selective Adsorption of Fluoroquinolones From Water. Int. J. Biol. Macromolecules. 107, 453-462. doi:10.1016/ j.ijbiomac.2017.09.009

Huang, L., Yu, W., Guo, X., Huang, Y., Zhou, Q., and Zhai, H. (2019a). Chip-Based Multi-Molecularly Imprinted Monolithic Capillary Array Columns Coated Fe3O4/GO for Selective Extraction and Simultaneous Determination of Tetracycline, Chlortetracycline and Deoxytetracycline in Eggs. Microchemical J. 150, 104097. doi:10.1016/j.microc.2019.104097

Huang, S., Chen, G., Ye, N., Kou, X., Zhu, F., Shen, J., et al. (2019b). Solid-Phase Microextraction: An Appealing Alternative for the Determination of Endogenous Substances - A Review. Analytica Chim. Acta. 1077, 67-86. doi:10.1016/j.aca.2019.05.054

Huang, W., Qing, Y., Wang, N., Lu, Y., Liu, T., Liu, T., et al. (2018). Novel Thermosensitive Core-Shell Surface Molecularly Imprinted Polymers Based on $\mathrm{SiO} 2$ for the Selective Adsorption of Sulfamethazine. Materials. 11, 2067. doi: $10.3390 / \mathrm{ma1} 1112067$

Ji, S., Li, T., Yang, W., Shu, C., Li, D., Wang, Y., et al. (2018). A Hollow Porous Molecularly Imprinted Polymer as a Sorbent for the Extraction of 7 Macrolide Antibiotics Prior to Their Determination by HPLC-MS/MS. Microchim Acta. 185, 203. doi:10.1007/s00604-018-2728-3

Kechagia, M., Samanidou, V., Kabir, A., and Furton, K. G. (2018). One-pot Synthesis of a Multi-Template Molecularly Imprinted Polymer for the Extraction of Six Sulfonamide Residues From Milk before HighPerformance Liquid Chromatography With Diode Array Detection. J. Sep. Sci. 41, 723-731. doi:10.1002/jssc.201701205

Kunsa-Ngiem, S., Sutthivaiyakit, P., Lowmunkhong, P., Harir, M., SchmittKopplin, P., and Sutthivaiyakit, S. (2018). Magnetic Molecularly Imprinted 
Polymer Prepared by Microwave Heating for Confirmatory Determination of Chloramphenicol in Chicken Feed Using High-Performance Liquid Chromatography-Tandem Mass Spectrometry. J. Environ. Sci. Health B. 53, 738-745. doi:10.1080/03601234.2018.1480161

Lamaoui, A., Palacios-Santander, J. M., Amine, A., and Cubillana-Aguilera, L. (2021). Fast Microwave-Assisted Synthesis of Magnetic Molecularly Imprinted Polymer for Sulfamethoxazole. Talanta. 232, 122430. doi:10.1016/j.talanta.2021.122430

Li, J., Wen, Y., and Chen, L. (2013). Advances of Molecularly Imprinted Polymers for Solid Phase Extraction. Se Pu. 31, 181-184. doi:10.3724/ sp.j.1123.2012.12029

Li, G., Zha, J., Niu, M., Hu, F., Hui, X., Tang, T., et al. (2018a). Bifunctional Monomer Molecularly Imprinted Sol-Gel Polymers Based on the Surface of Magnetic Halloysite Nanotubes as an Effective Extraction Approach for Norfloxacin. Appl. Clay Sci. 162, 409-417. doi:10.1016/j.clay.2018.06.003

Li, Z., Lei, C., Wang, N., Jiang, X., Zeng, Y., Fu, Z., et al. (2018b). Preparation of Magnetic Molecularly Imprinted Polymers With Double Functional Monomers for the Extraction and Detection of Chloramphenicol in Food. J. Chromatogr. B. 1100-1101, 113-121. doi:10.1016/j.jchromb.2018.09.032

Li, J., Wang, J., Xu, K., Liu, K., Peng, S., Lin, Z., et al. (2020a). Research Progress in the Detection and Removal of Beta-Lactam Antibiotics. Appl. Chem. Ind. 49, 1541-1546. doi:10.16581/j.cnki.issn1671-3206.20200330.010

Li, J., Zhou, Y., Sun, Z., Cai, T., Wang, X., Zhao, S., et al. (2020b). Restricted Access Media-imprinted Nanomaterials Based on a Metal-Organic Framework for Highly Selective Extraction of Fluoroquinolones in Milk and River Water. J. Chromatogr. A. 1626, 461364. doi:10.1016/j.chroma.2020.461364

Li, X., and Row, K. H. (2017). Purification of Antibiotics from the Millet Extract Using Hybrid Molecularly Imprinted Polymers Based on Deep Eutectic Solvents. RSC Adv. 7, 16997-17004. doi:10.1039/c7ra01059a

Li, H., and Wang, J. (2020). Research Progress of Molecular Imprinted Nanomaterials. China Powder Sci. Technol. 26, 22-28. doi:10.13732/ j.issn.1008-5548.2020.01.004

Li, Y., Zhou, Q., Chen, Y., Lin, Z., Qi, P., and Mao, X. (2019). Research Progress of Magnetic Solid Phase Extraction in Food Analysis. Sci. Technol. Food Ind. 40, 323-336. doi:10.13386/j.issn1002-0306.2019.08.054

Lian, Z., and Wang, J. (2018). Selective Detection of Chloramphenicol Based on Molecularly Imprinted Solid-Phase Extraction in Seawater From Jiaozhou Bay, China. Mar. Pollut. Bull. 133, 750-755. doi:10.1016/ j.marpolbul.2018.06.041

Liang, J., Huang, Y., and He, J. (2018a). Application of Magnetic Molecularly Imprinted Polymers in Food Safety Testing. J. Qi Lu Univ. Technology. 32, 39-42. doi:10.16442/j.cnki.qlgydxxb.2018.04.006

Liang, Y., Song, L., Bu, T., Li, Y., Ba, X., He, J., et al. (2018b). Synthesis and Characterization of Sulfa Drugs Imprinted Polymers by Atom Transfer Radical Polymerization With Fragment Imprinting. J. Instrum. Anal. 37, 82-86. doi:10.3969/j.issn.1004-4957.2018.01.013

Liang, M., and Zhang, X. (2021). Research Progress on Detection of Macrolide Residues in Aquatic Product. J. Food Saf. Qual. 12, 595-601. doi:10.19812/ j.cnki.jfsq11-5956/ts.2021.02.034

Liang, T., Gao, L., Qin, D., and Chen, L. (2019). Determination of Sulfonylurea Herbicides in Grain Samples by Matrix Solid-Phase Dispersion with Mesoporous Structured Molecularly Imprinted Polymer. Food Anal. Methods. 12, 1938-1948. doi:10.1007/s12161-019-01539-y

Liu, H., Zhou, Y., Qi, Y., Sun, Z., and Gong, B. (2018). Preparation of Thiamphenicol Magnetic Surface Molecularly Imprinted Polymers for its Selective Recognition of Thiamphenicol in Milk Samples. J. Liquid Chromatogr. Relat. Tech. 41, 868-879. doi:10.1080/10826076.2018.1531294

Liu, L., Yang, B., Zhang, F., and Liang, X. (2017). A Magnetic Restricted Access Material for Rapid Solid Phase Extraction of Multiple Macrolide Antibiotics in Honey. Anal. Methods. 9, 2990-2996. doi:10.1039/c7ay00478h

Liu, P., Wang, X., and Feng, L. (2020). Occurrences Resources and Risk of Antibiotics in Aquatic Environment: A Review. Environ. Eng. (Beijing, China). 38, 36-42. doi:10.13205/j.hjgc.202005007

Liu, Y., Yang, Q., Chen, X., Song, Y., Wu, Q., Yang, Y., et al. (2019). Sensitive Analysis of Trace Macrolide Antibiotics in Complex Food Samples by Ambient Mass Spectrometry With Molecularly Imprinted Polymer-Coated Wooden Tips. Talanta. 204, 238-247. doi:10.1016/j.talanta.2019.05.102

Lu, W., Liu, J., Li, J., Wang, X., Lv, M., Cui, R., et al. (2019). Dual-Template Molecularly Imprinted Polymers for Dispersive Solid-Phase Extraction of
Fluoroquinolones in Water Samples Coupled with High Performance Liquid Chromatography. Analyst. 144, 1292-1302. doi:10.1039/c8an02133c

Ma, W., and Row, K. H. (2019). Simultaneous Determination of Levofloxacin and Ciprofloxacin in Human Urine by Ionic-Liquid-Based, Dual-Template Molecularly Imprinted Coated Graphene Oxide Monolithic Solid-phase Extraction. J. Sep. Sci. 42, 642-649. doi:10.1002/jssc.201800939

Ma, Z., He, J., Zhao, T., and Zhao, X. (2020). Study on Preparation of Tetracyline Magnetic Molecularly Imprinted Biochar Microspheres Based on Pickering Emulsion Polymerization. Food and Machinery. 36, 70-75+94. doi:10.13652/ j.issn.1003-5788.2020.05.013

Ming, Q., Ou, X., Zhang, M., Zhao, L., and Yun, Y. (2021). Research Progress of Antibiotics and Antibiotic Wastewater Treatment Technology. J. Green Sci. Technology. 23, 81-83. doi:10.16663/j.cnki.lskj.2021.02.028

Nascimento, T. A., Silva, C. F., Oliveira, H. L. d., da Silva, R. C. S., Nascimento, C. S., Jr., and Borges, K. B. (2020). Magnetic Molecularly Imprinted Conducting Polymer for Determination of Praziquantel Enantiomers in Milk. Analyst. 145, 4245-4253. doi:10.1039/d0an00703j

Nazario, C. E. D., Fumes, B. H., da Silva, M. R., and Lanças, F. M. (2017). New Materials for Sample Preparation Techniques in Bioanalysis. J. Chromatogr. B. 1043, 81-95. doi:10.1016/j.jchromb.2016.10.041

Negarian, M., Mohammadinejad, A., and Mohajeri, S. A. (2019). Preparation, Evaluation and Application of Core-Shell Molecularly Imprinted Particles as the Sorbent in Solid-Phase Extraction and Analysis of Lincomycin Residue in Pasteurized Milk. Food Chem. 288, 29-38. doi:10.1016/ j.foodchem.2019.02.087

Płotka-Wasylka, J., Szczepańska, N., de la Guardia, M., and Namieśnik, J. (2016). Modern Trends in Solid Phase Extraction: New Sorbent media. Trac, Trends Anal. Chem. 77, 23-43. doi:10.1016/j.trac.2015.10.010

Qin, D., Wang, J., Ge, C., and Lian, Z. (2019). Fast Extraction of Chloramphenicol From Marine Sediments by Using Magnetic Molecularly Imprinted Nanoparticles. Microchim. Acta. 186, 428. doi:10.1007/s00604-019-3548-9

Qin, D., Zhao, M., Wang, J., and Lian, Z. (2020). Selective Extraction and Detection of Norfloxacin From Marine Sediment and Seawater Samples Using Molecularly Imprinted Silica Sorbents Coupled with HPLC. Mar. Pollut. Bull. 150, 110677. doi:10.1016/j.marpolbul.2019.110677

Reyes-Garcés, N., Gionfriddo, E., Gómez-Ríos, G. A., Alam, M. N., Boyacı, E., Bojko, B., et al. (2018). Advances in Solid Phase Microextraction and Perspective on Future Directions. Anal. Chem. 90, 302-360. doi:10.1021/ acs.analchem.7b04502

Rodríguez-Gómez, R., García-Córcoles, M. T., Çipa, M., Barrón, D., Navalón, A., and Zafra-Gómez, A. (2018). Determination of Quinolone Residues in Raw Cow Milk. Application of Polar Stir-Bars and Ultra-high Performance Liquid Chromatography-Tandem Mass Spectrometry. Food Additives \& Contaminants: A. 35, 1127-1138. doi:10.1080/19440049.2018.1430382

Soares, K. L., Sunyer-Caldú, A., Barbosa, S. C., Primel, E. G., Fillmann, G., and Diaz Cruz, M. S. (2021). Rapid and Cost-Effective Multiresidue Analysis of Pharmaceuticals, Personal Care Products, and Antifouling Booster Biocides in Marine Sediments Using Matrix Solid Phase Dispersion. Chemosphere. 267, 129085. doi:10.1016/j.chemosphere.2020.129085

Song, X., Zhou, T., Li, J., Su, Y., Xie, J., and He, L. (2018). Determination of Macrolide Antibiotics Residues in Pork Using Molecularly Imprinted Dispersive Solid-phase Extraction Coupled with LC-MS/MS. J. Sep. Sci. 41, 1138-1148. doi:10.1002/jssc.201700973

Song, X., Zhou, T., Zhang, J., Su, Y., Zhou, H., and He, L. (2019). Preparation and Application of Molecularly Imprinted Monolithic Extraction Column for the Selective Microextraction of Multiple Macrolide Antibiotics from Animal Muscles. Polymers. 11, 1109. doi:10.3390/polym11071109

Song, Y. P., Zhang, L., Wang, G. N., Liu, J. X., Liu, J., and Wang, J. P. (2017). DualDummy-Template Molecularly Imprinted Polymer Combining Ultra Performance Liquid Chromatography for Determination of Fluoroquinolones and Sulfonamides in Pork and Chicken Muscle. Food Control. 82, 233-242. doi:10.1016/j.foodcont.2017.07.002

Stachelek, M., Zalewska, M., Kawecka-Grochocka, E., Sakowski, T., and Bagnicka, E. (2021). Overcoming Bacterial Resistance to Antibiotics: The Urgent Need-a Review. Ann. Anim. Sci. 21, 63-87. doi:10.2478/aoas-2020-0098

Tan, L., Li, Y., Pan, X., Marina, M. L., and Jiang, Z. (2020). Boronate Affinity Glycosyl Molecularly Imprinted Polymer Microspheres for the Determination of Teicoplanin Using Ultra-high Performance Liquid Chromatography 
Coupled With Tandem Mass Spectrometry. J. Chromatogr. A. 1615, 460776. doi:10.1016/j.chroma.2019.460776

Tang, J., Wang, J., Yuan, L., Xiao, Y., Wang, S., and Wang, X. (2019). Dummy Molecularly Imprinted Matrix Solid-Phase Dispersion for Selective Extraction of Seven Estrogens in Aquatic Products. Food Anal. Methods. 12, 2241-2249. doi:10.1007/s12161-019-01575-8

Teixeira, R. A., Flores, D. H. Â., da Silva, R. C. S., Dutra, F. V. A., and Borges, K. B. (2018). Pipette-tip Solid-Phase Extraction Using Poly(1-Vinylimidazole-CoTrimethylolpropane Trimethacrylate) as a New Molecularly Imprinted Polymer in the Determination of Avermectins and Milbemycins in Fruit Juice and Water Samples. Food Chem. 262, 86-93. doi:10.1016/ j.foodchem.2018.04.076

Tian, H., Liu, T., Mu, G., Chen, F., He, M., You, S., et al. (2020). Rapid and Sensitive Determination of Trace Fluoroquinolone Antibiotics in Milk by Molecularly Imprinted Polymer-Coated Stainless Steel Sheet Electrospray Ionization Mass Spectrometry. Talanta. 219, 121282. doi:10.1016/j.talanta.2020.121282

Wang, J., Du, Z., Wang, Y., Cao, Y., Ma, L., Feng, Y., et al. (2018a). Rapid Determination of Quinolone and Sulfonamides in Milk by Filtration Solid Phase Extraction-Ultra Performance Liquid Chromatography-Tandem Mass Spectrometry. Chin. J. Anal. Lab. 37, 599-603. doi:10.13595/j.cnki.issn10000720.2018 .0113

Wang, S., Zhang, J., Li, C., and Chen, L. (2018b). Analysis of Tetracyclines From Milk Powder by Molecularly Imprinted Solid-Phase Dispersion Based on a Metal-Organic Framework Followed by Ultra High Performance Liquid Chromatography With Tandem Mass Spectrometry. J. Sep. Sci. 41, 2604-2612. doi:10.1002/jssc.201701514

Wang, X., Li, J., and Chen, L. (2019). Advanced Preparation Technologies and Strategies for Molecularly Imprinted Materials. Chin. Sci. Bull. 64, 1352-1367. doi:10.1360/N972018-00964

Wang, Z., and Cao, X. (2015). Preparation of Core-Shell Molecular Imprinting Polymer for Lincomycin A and its Application in Chromatographic Column. Process Biochem. 50, 1136-1145. doi:10.1016/j.procbio.2015.04.013

Wei, S., Li, J., Liu, Y., and Ma, J. (2016). Development of Magnetic Molecularly Imprinted Polymers With Double Templates for the Rapid and Selective Determination of Amphenicol Antibiotics in Water, Blood, and Egg Samples. J. Chromatogr. A. 1473, 19-27. doi:10.1016/j.chroma.2016.10.067

Wu, A., Zhao, X., Wang, J., Tang, Z., Zhao, T., Niu, L., et al. (2021). Application of Solid-Phase Extraction Based on Magnetic Nanoparticle Adsorbents for the Analysis of Selected Persistent Organic Pollutants in Environmental Water: A Review of Recent Advances. Crit. Rev. Environ. Sci. Technology. 51, 44-112. doi:10.1080/10643389.2020.1720493

Xie, Y., Hu, Q., Zhao, M., Cheng, Y., Guo, Y., Qian, H., et al. (2018). Simultaneous Determination of Erythromycin, Tetracycline, and Chloramphenicol Residue in Raw Milk by Molecularly Imprinted Polymer Mixed with Solid-Phase Extraction. Food Anal. Methods. 11, 374-381. doi:10.1007/s12161-017-1008-x

Xu, Y., Li, J., Jiang, L., Li, Z., Li, Y., and Ding, L. (2018). Simultaneous Determination of Sulfonamides and Fluoroquinolones from Environmental Water Based on Magnetic Double-Template Molecularly Imprinting Technique. Environ. Sci. Pollut. Res. 25, 16121-16134. doi:10.1007/s11356018-1581-6

Yang, K., Wang, G. N., Liu, H. Z., Liu, J., and Wang, J. P. (2017). Preparation of Dual-Template Molecularly Imprinted Polymer Coated Stir Bar Based on Computational Simulation for Detection of Fluoroquinolones in Meat. J. Chromatogr. B. 1046, 65-72. doi:10.1016/j.jchromb.2017.01.033
Yu, R., Chen, L., Shen, R., Li, P., and Shi, N. (2020). Quantification of Ultratrace Levels of Fluoroquinolones in Wastewater by Molecularly Imprinted Solid Phase Extraction and Liquid Chromatography Triple Quadrupole Mass. Environ. Technology Innovation. 19, 100919. doi:10.1016/j.eti.2020.100919

Zhang, X., Wang, X., Xie, X., Cheng, Z., and Li, C. (2021). Research Progress on Residue Analysis of Chloramphenicol in Animal-Derived Food. Chin. Vet. Sci. 51, 920-924. doi:10.16656/j.issn.1673-4696.2021.0109

Zhang, Y., Qian, S., Zhao, Z., E, H., Fan, T., Li, X., et al. (2020a). Advances on Application of Solid Phase Extraction in Analysis of Sulfonamides Residues. J. Instrum. Anal. 39, 681-687. doi:10.3969/j.issn.10044957.2020.05.019

Zhang, Z., Cao, X., Zhang, Z., Yin, J., Wang, D., Xu, Y., et al. (2020b). Synthesis of Dummy-Template Molecularly Imprinted Polymer Adsorbents for Solid Phase Extraction of Aminoglycosides Antibiotics from Environmental Water Samples. Talanta. 208, 120385. doi:10.1016/j.talanta.2019.120385

Zhao, X., Lü, L., Zhu, M., Liu, H., He, J., and Zheng, F. (2021). Development of Hydrophilic Magnetic Molecularly Imprinted Polymers for the Dispersive Solid-Phase Extraction of Sulfonamides From Animal-derived Samples before HPLC Detection. J. Sep. Sci. 44, 2399-2407. doi:10.1002/jssc.202001244

Zhao, X., Wang, J., Wang, J., and Wang, S. (2018). Development of WaterCompatible Molecularly Imprinted Solid-Phase Extraction Coupled With High Performance Liquid Chromatography-Tandem Mass Spectrometry for the Detection of Six Sulfonamides in Animal-Derived Foods. J. Chromatogr. A. 1574, 9-17. doi:10.1016/j.chroma.2018.08.044

Zhu, G., Cheng, G., Wang, L., Yu, W., Wang, P., and Fan, J. (2019a). A New Ionic Liquid Surface-imprinted Polymer for Selective Solid-phase-extraction and Determination of Sulfonamides in Environmental Samples. J. Sep. Sci. 42, 725-735. doi:10.1002/jssc.201800759

Zhu, G., Cheng, G., Wang, P., Li, W., Wang, Y., and Fan, J. (2019b). Water Compatible Imprinted Polymer Prepared in Water for Selective Solid Phase Extraction and Determination of Ciprofloxacin in Real Samples. Talanta. 200, 307-315. doi:10.1016/j.talanta.2019.03.070

Zhu, G., Li, W., Wang, L., Wang, P., Shi, D., Wang, J., et al. (2019c). Using Ionic Liquid Monomer to Improve the Selective Recognition Performance of Surface Imprinted Polymer for Sulfamonomethoxine in strong Polar Medium. J. Chromatogr. A. 1592, 38-46. doi:10.1016/j.chroma.2019.01.053

Conflict of Interest: The authors declare that the research was conducted in the absence of any commercial or financial relationships that could be construed as a potential conflict of interest.

Publisher's Note: All claims expressed in this article are solely those of the authors and do not necessarily represent those of their affiliated organizations, or those of the publisher, the editors and the reviewers. Any product that may be evaluated in this article, or claim that may be made by its manufacturer, is not guaranteed or endorsed by the publisher.

Copyright $\odot 2021$ Sun, Song, Zhang, Wang, Lv, Liu, Wang, Lu, Li and Chen. This is an open-access article distributed under the terms of the Creative Commons Attribution License (CC BY). The use, distribution or reproduction in other forums is permitted, provided the original author(s) and the copyright owner(s) are credited and that the original publication in this journal is cited, in accordance with accepted academic practice. No use, distribution or reproduction is permitted which does not comply with these terms. 